\title{
The Optimal Length of Contracts with Application to Outsourcing
}

\author{
Matthew Ellman* \\ Universitat Pompeu Fabra
}

February, 2006

\begin{abstract}
This paper resolves three empirical puzzles in outsourcing by formalizing the adaptation cost of long-term performance contracts. Side-trading with a new partner alongside a longterm contract (to exploit an adaptation-requiring investment) is usually less effective than switching to the new partner when the contract expires. So long-term contracts that prevent holdup of specific investments may induce holdup of adaptation investments. Contract length therefore trades off specific and adaptation investments. Length should increase with the importance and specificity of self-investments, and decrease with the importance of adaptation investments for which side-trading is ineffective. My general model also shows how optimal length falls with cross-investments and wasteful investments.
\end{abstract}

Jel Classification numbers: D23.

KEYwORDS: Contract length; market forces; incomplete contracts; holdup.

${ }^{*}$ I thank Erik Beulen, Ramon Campabadal, Oliver Hart, Ashok Kaul, Eric Maskin, Elisenda Monforte, Michael Raith, Jan Sarsanedas, Andrei Shleifer, Jérôme Vandenbussche, Abe Wickelgren and seminar participants at ASSA (2005), the Toulouse IDEI Conference in Honor of Jean-Jacques Laffont (2005), the Harvard Kennedy School, the Kellogg School of Management, and Autonoma de Barcelona, Northwestern, Tilburg, Torcuato di Tella Universities for helpful comments. I gratefully acknowledge financial support from the European Commission (HPMF-CT-1999-00317), the Spanish Ministry of Science and Technology (BEC 2003-00412) and CREA (Barcelona Economics). Comments gratefully received at Matthew.Ellman@upf.edu. 


\section{Introduction}

Transactions Cost and Incomplete Contract theorists have shown how long-term contracts help protect relationship-specific investments (see Williamson, 1975 and 1985, Klein, Crawford and Alchian, 1978, and the formalization in Grout, 1984), but we know little about the costs of extending contract length. This paper formalizes a simple yet powerful idea: long-term contracts may obstruct beneficial market forces. My conceptual contribution is to show how and when this market-shielding cost arises. I also formalize two other major costs of contract duration. I then represent the costs and benefits of contract duration within a single theoretical model in order to derive optimal contract length. Using the market-shielding results alone, the paper is able to resolve three significant puzzles from the empirical literature. My framework also throws light on the practical challenge of designing flexible long-term contracts.

Contracts vary greatly in length. Multi-year contracts are common in, for example, construction, contract manufacturing, distribution, franchising and Information Technology (IT). Outsourcing in IT presents an instructive showcase. ${ }^{1}$ For instance, IBM Global Services sells IT services to Nokia, Hertz, American Express (Amex) and Deutsche-Bank (DB) under 5, 6, 7 and 10 year contracts, respectively. I will use IBM's \$4bn deal with Amex (see Weiss, 2002) to illustrate the main ideas of the paper. Signed in February of 2002, the contract essentially obliges IBM to manage and maintain Amex's Information System (IS) at a predetermined price. I call this exchange the "basic trade." ${ }^{2}$ The contract duration is 7 years - it enforces the basic trade from 2002 till 2009 - but through renegotiation and renewal, Amex could have paid IBM to provide the same services under a sequence of longer or shorter contracts. I therefore ask: what are the costs and benefits of increasing contract length?

I begin with an example of the now familiar benefits. IBM invested in organization and planning to lower its costs of managing Amex's Information System. Many of these investments are partly specific to Amex. For instance, IBM coached 2000 workers who transferred from Amex to IBM in 2002. This reduced IBM's cost of servicing Amex, but the transferred workers' specific knowledge of Amex does not help IBM in servicing other clients. So IBM must sell services to Amex if it is to fully exploit its cost-reducing investment. Under shortterm contracting, Amex could therefore extract a share of the cost-reduction by refusing to buy unless IBM lowers its price. This "holdup" by Amex reduces IBM's investment returns,

\footnotetext{
${ }^{1}$ The IT outsourcing market was worth over $\$ 569 \mathrm{bn}$ in 2003, up 6.2\% from 2002 (Pruitt, 2004). US government IT outsourcing hit $\$ 8.5 \mathrm{bn}$ in 2003 and is likely to exceed $\$ 15$ bn by 2008 (Input, 2004). The UK National Health Service alone awarded five IT contracts in January 2004, each 10 years long and worth over $\$ 1$ bn.

${ }^{2}$ The contract actually specifies a range of prices (see section 6). It covers infrastructure (data center, networks and desktops) and application software, but is basic relative to subsequently discovered adaptations.
} 
so it causes IBM to underinvest. The long-term contract serves to protect IBM's investment against holdup by fixing the price Amex pays for the basic trade. Lengthening the contract raises IBM's incentives by increasing the duration of this protection.

The long-term contract can also protect IBM-specific investments by Amex. For instance, when Amex learns to make better use of the basic IT from IBM, the contract prevents IBM from holding up Amex by raising the trade price. In general, long-term contracts protect specific investments that raise the investor's own payoff from the basic trade. These are called "self-investments" (MacLeod and Malcomson, 1993). Motivating self-investments is the key benefit of long-term contracting. I now turn to my contributions which deal with the costs.

My primary contribution is to identify the market-shielding cost of contracting. Consider what happens when Amex invests in market research and discovers a valuable IT innovation. For instance, Amex planned a web-based expense reporting service for its corporate customers in 2003. To exploit this innovation, Amex needed an adapted IT service with new software and third-party web access. The long-term contract did not oblige IBM to provide the adapted system, since it was not included in the basic trade. So Amex had to adapt its contracts to exploit its investment, which I therefore define as an "adaptation investment." Amex had two choices: either negotiate a deal with IBM or pay a competitor to make the changes.

Without the long-term contract, both alternatives would have been reasonable. Amex could have paid IBM to switch to providing the adapted service, or it could have stopped buying from IBM and negotiated provision of the adapted service from one of IBM's competitors, such as Electronic Data Systems (EDS). IBM may have sunk costs specific to Amex, but in default of trade with IBM, Amex would credibly pay EDS to sink its avoidable start-up costs. Market forces - here Amex's threat of using EDS - therefore limit the price that IBM can charge for the adaptation. This ensures that Amex can earn a reasonable return on its investment.

Unfortunately, the long-term contract shields the relationship from these market forces: Amex was unable to credibly threaten to buy the adapted service from EDS alongside the basic service from IBM. The adapted service would have mostly duplicated the basic service and its additional value (given Amex's limited service need) did not justify EDS's avoidable costs of substituting for IBM. ${ }^{3}$ As a result, Amex depended on IBM to exploit its adaptation. IBM was therefore able to hold up Amex by charging a high price for adaptation. Anticipating this holdup, Amex has less incentive to invest in adaptations.

Long-term contracts do not always cause holdup of adaptation investments, because side-

\footnotetext{
${ }^{3}$ Breach of the long-term contract would avoid duplication of the basic service. Breach is common after mergers, but I follow Tirole (1990, page 54) in defining long-term contracts as those with breach penalties that enforce future performance. In 6.2, I generalize to stochastic breach.
} 
trading (i.e. accessing market alternatives alongside the long-term contract) is sometimes feasible. For instance, had Amex been able to separate the adapted service into a basic service and an adaptation service, Amex might have turned to EDS for the adaptation alone as a side-trade complementing (instead of duplicatively substituting) the basic trade with IBM. Amex's threat of buying from EDS alongside the contract with IBM would then protect Amex's investment from holdup.

The effectiveness of side-trading threats is highest when the adaptation and basic trades are least related, because separating provision of the basic and adaptation tasks between two providers (such as EDS and IBM) wastes any economies of scope. For instance, both tasks might require the same fixed costs of learning about Amex. Also, separation may cause coordination and interference problems. For instance, IBM could refuse to provide user-support or third-party web access for software developed by EDS, or IBM could abuse its power as IT host to study EDS's proprietary code (see section 6). These are precisely the settings where practitioners warn of flexibility problems (see section 2 ).

To formalize, I define the "side-compatibility" of an adaptation investment with a long-term contract to be the fraction of investment returns that the investor (here the buyer, Amex) can credibly exploit through side-trading (alongside the contract). Under full side-compatibility, the investor can threaten to turn to the market as effectively during a long-term contract as under short-term contracting. In this special case, long-term contracts do not induce holdup of adaptation investments. More generally, the "market-shielding" cost of long-term contracts decreases with the side-compatibility of desirable adaptation investments. So higher sidecompatibility permits traders to write longer contracts.

This simple point is central to my applications in section 6 . Here, I briefly summarize how the three design issues of section 6 - multi-sourcing, buyer dedication, and exclusive contracting - allow me to resolve the three empirical puzzles. The first issue is choosing whether to multisource, wherein the buyer deals with multiple vendors (sources). For instance, suppose back in 2002, Amex had split its basic needs between two vendors by contracting IBM to maintain its servers and networks, while contracting EDS to manage its desktop environment, applications software and help-desk. ${ }^{4}$ This would have wasted possible economies of scope by making both EDS and IBM sink fixed costs in learning about Amex. The main advantage is that EDS and IBM would then have competed for more of Amex's subsequent adaptations: multi-sourcing raises side-compatibility.

This result resolves an interesting empirical puzzle. Transaction cost theory informally pre-

\footnotetext{
${ }^{4}$ Multisourcing is increasingly common in IT - e.g., Procter \& Gamble recently rejected a mega-contract with EDS in favour of smaller contracts with HP, IBM and Jones, Lang \& Lasalle (see 6.3); see also Singer (2004).
} 
dicts shorter contract durations for companies that buy from multiple vendors: the multiplicity of active suppliers suggests high competition, so investment specificity and the resulting need for long-term contracting is low. (In proposition 5 below, I formally prove that optimal contract length is indeed increasing in specificity.) However, the evidence from electronics outsourcing (López and Ventura, 2001, and González and López, 2002) suggests that multi-sourcers tend, if anything, to use longer contracts. My theory helps to explain the puzzle: multi-sourcers can write longer contracts, because side-compatibility is high and this lowers the market-shielding cost of contracting.

To treat the second puzzle, I apply the concept of side-compatibility to adaptation investments by sellers (vendors). Suppose IBM develops a more secure IT service (e.g., by investing in asynchronous chip technology - see the Economist, 2001). IBM has a huge capacity so it could earn a market reward alongside the basic trade with Amex, by selling this adapted service to other buyers. However, for a smaller IT company, a long-term contract may limit side-compatibility by tying up most of the company's production capacity. Limited production capacity of the seller plays a role parallel to that of the buyer's limited consumption need (such as Amex's need for just one IT service).

Companies usually design their long-term contracts to employ only a fraction of their capacity, but economies of scale sometimes encourage a seller to dedicate most or all of its capacity to a single buyer. Side-compatibility is then very limited. This can resolve a second empirical puzzle. Kerkvliet and Shogren (2001) measure how far coal companies dedicate capacity to satisfying contracts with specific clients. These scholars predicted that contract length would correlate positively with dedication since dedication is a standard proxy for relationship-specificity, but they found that the most dedicated coal companies actually tend to write shorter contracts. The side-compatibility concept identifies a countervailing force that can explain their puzzling result: dedication lowers side-compatibility, thereby raising the cost of long-term contracting.

Bercovitz (2000) uncovered the third empirical puzzle in data on franchising. Exclusive territories complement long-term performance contracts in protecting specific investments by franchisees, so Bercovitz (2000) predicted a positive correlation, but she found the opposite. The side-compatibility concept can explain this puzzle: contracts should be shorter when exclusivity is needed, because exclusivity clauses directly lower side-compatibility. To see why, notice that if Amex had committed to buy all its IT from IBM, it could never threaten to seek an IT adaptation from a third party. ${ }^{5}$

\footnotetext{
${ }^{5}$ Unsurprisingly, IT contracts often actively oppose exclusivity. E.g., M\&I's contract with Tri City obliges M\&I to cooperate with third-party providers, and GM's 10-year $\$ 32$ bn contract with EDS includes a "right to
} 
To increase the relevance of my model, I generalize it in section 4 to capture two other major costs of long-term contracting. First, long-term contracts reduce incentives to make investments with positive contractual externalities. For instance, when IBM investments improve storage efficiency, Amex benefits since the pay-as-you-use formula in the long-term contract with IBM fixes a price per unit of server space used. Unlike IBM's cost-cutting self-investment that raises IBM's own payoff, this is a "cross-investment" ${ }^{6}$ by IBM because it benefits Amex (the other party). The long-term contract reduces IBM's incentive to improve storage efficiency, because it prevents Amex from punishing low efficiency with a termination threat (see Hoffman, 2002, for evidence of this incentive cost). Second, long-term contracting can encourage wasteful self-investments. For instance, IBM might waste resources trying to hide low quality aspects of its service or litigating Amex (see CORI on EDS-Xerox, 1994). Similarly, long-term contracts can cause over-investment when a self-investment has negative cross-investment effects (e.g., lowering quality). My model shows that short-term contracting avoids all these problems, but introduces parallel problems for investments with "cross-general" effects (i.e., effects on other party's market payoffs).

The secondary contribution of this paper is to formulate a generic model of trade between two parties with multiple investments. My first set of results characterizes how different investments respond to changes in contract length. I classify investments into two types. Self-investments and cross-general investments are type 1 (contract-ophilic). They rise with contract length. Adaptation investments with limited side-compatibility and cross-investments are type 2 (contract-ophobic). They fall with contract length. I then use these results to determine how contract length optimally trades off investments based on their relative desirability. My second set of results can be summarized as: optimal contract length increases with (1) the desirability of type 1 relative to type 2 investments; (2) the relationship-specificity of type 1 investments; and (3) the side-compatibility of type 2 investments.

The rich literature on contract design in microeconomics (see Holmström and Milgrom, 1991, or Salanié, 1997) tends to ignore a key factor: discoveries are made over time. I follow the "incomplete contracting approach" (see Hart, 1995) in emphasizing unanticipated discoveries, but my results do not require shifts in the residual rights of control. ${ }^{7} \mathrm{My}$ focus on the time dimension of contracting complements the literatures on damage measures (see Rogerson, 1984, and Shavell, 1984) and variable quantity contracts (see Edlin and Reichelstein, 1996). In

solicit bids" (CORI).

${ }^{6}$ Che and Hausch (1999) call it "cooperative investment" but see Ellman (1999 and 2006) or Watson (2003).

${ }^{7} \mathrm{I}$ isolate the role of contractual obligations to trade (c.f., Hart, Shleifer and Vishny, 1997, where long-term contracting is tied to privatization of ownership). 
section 4, I use Hart et al.'s (1997) over-investment insight and Che and Hausch's (1999) model of how long-term contracts harm cross-investments. Farrell and Shapiro (1989), MacLeod and Malcomson (1993) and Guriev and Kvassov (2006) offer complementary studies of contracting over multiple trading periods. None of these papers capture the market-shielding problem because they do not allow for adaptation investments. ${ }^{8}$

The literature on transaction costs (see Williamson, 1985) presents vital insights. Joskow's (1987) empirical support for the idea that contract length should increase with relationshipspecificity (as proxied by limited competitive alternatives) has become a classic, and has been confirmed in several industries (see Masten and Saussier, 2002). My propositions 4 and 5 formalize this idea. Furthermore, because uncertainty and complexity raise the importance of ongoing adaptations (and raise the risk that contracts motivate undesirable investments), my theory explains the growing evidence that these factors lead to shorter contracts. ${ }^{9}$ Finally, my analysis refines the transaction cost idea that long-term contracts can cause inflexibility, and suggests an explanation of ex post adaptation failure.

The paper is organized as follows. Section 2 presents the basic model. Section 3 solves it for optimal contract length. Section 4 introduces cross effects and wasteful investments. Section 5 extends the number of trading periods. Section 6 endogenizes side-compatibility through empirically motivated features of contract design, and applies the theoretical results to explain the empirical puzzles. Section 7 concludes.

\section{Basic Model}

This section introduces a simple model to analyze how advance commitment to an (imperfect) formal contract affects the efficiency of a bilateral relationship embedded within a market. I denote the central actors by $\mathrm{P}$ for principal and A for agent; buyer-seller interpretations are also valid and I refer to all interactions as trades. Until section 5, I adopt a simplified timing: when P and A meet in stage 0 (February 2002 in Amex and IBM's case), they can negotiate an initial contract to govern stage 3 trade. In stage $1, \mathrm{P}$ and $\mathrm{A}$ invest to raise trade surplus. In stage 2, after observing their trade values, they finalize the contracts that will govern their joint and market trading in stage 3 .

Contracting. Advance contracting is restricted by $\mathrm{P}$ and A's bounded ability to think up ways to enforce future trades. In stage $0, \mathrm{P}$ and A can only choose between writing a "basic"

\footnotetext{
${ }^{8}$ MacLeod and Malcomson (1993) do include a general investment, but it is also protected by the long-term contract so there is no market-shielding problem.

${ }^{9}$ See Crocker and Masten (1988), Brickley et al (2003), González and López (2002) who respectively use price uncertainty, inexperience and subjective inexperience as proxies.
} 
performance contract, $X$, and writing a "null" contract, $\Phi$ (that does not enforce any stage 3 $\left.\operatorname{trade}^{10}\right)$. During stage 1 , they learn better ways to trade, so that by stage 2 , they can choose a contract from the set $\{\Phi, X, Z\}$ where $Z$ is the "adapted" contract that generates the highest surplus. Contracting is long-term when $\mathrm{P}$ and $\mathrm{A}$ commit at stage 0 to a performance contract $(X)$ before investing. Contracting is short-term when instead they initially select the null contract $\Phi$, leaving trade negotiation to the last minute (here, stage 2). (In the multi-period generalization in section 5 , contract length is the amount of time over which the initial contract enforces basic trade performance.)

Payoffs. P and A's payoffs depend on their investments and on stage 3 trade contracts. A typical investment, $e_{j} \in \mathbb{R}_{+}$by $j \in\{P, A\}$, imposes a private cost of $e_{j}$ on the investing party $j$ and increases $\mathrm{P}$ and A's optimized stage 3 trade surplus (the surplus under $Z$ ) by $W_{j}\left(e_{j}\right)$. However, in default of renegotiation between $\mathrm{P}$ and $\mathrm{A}, e_{j}$ only raises $j$ 's payoff under $\Phi$ by $\gamma_{e_{j}} W_{j}\left(e_{j}\right)$, and only raises $j$ 's payoff under $X$ by $\psi_{e_{j}} W_{j}\left(e_{j}\right)$. In the default under $\Phi$, there is no performance contract between $\mathrm{P}$ and $\mathrm{A}$, so $\gamma_{e_{j}}$ represents $j$ 's fractional return on $e_{j}$ after $j$ switches to $j$ 's best alternative (market) trade. In the case of a specific investment, $\gamma_{e_{j}}<1$ because $j$ 's investment is then more effective in joint trading. Since $\gamma_{e_{j}}=0$ for a fully specific investment and $\gamma_{e_{j}}=1$ for a fully general investment, I call $\gamma_{e_{j}}$ the generality of $e_{j}$. Meanwhile, in the default under $X, j$ engages in the basic trade with $-j(-j$ denotes $A$ if $j=P$ and $P$ if $j=A$ ) and a side-trading response to $X$. So $\psi_{e_{j}}$ represents $j$ 's fractional return on $e_{j}$ from both the basic trade induced by long-term contracting on $X$ and the optimal side-trade; $\psi_{e_{j}}$ effectively sums $e_{j}$ 's self-investment effect (direct compatibility with contract $X)$ and $e_{j}$ 's side-compatibility (see introduction and definition below).

Existing work assumes that $\psi_{e_{j}} \geq \gamma_{e_{j}}$. This reflects how the long-term contract $(X)$ may guarantee $j$ a better investment return than afforded by market trading - $\psi_{e_{j}}$ then reflects how well the contract $X$ directly protects the investment. ${ }^{11}$ However, the opposite case, $\psi_{e_{j}}<\gamma_{e_{j}}$, is also feasible. This occurs when the long-term contract $X$ interferes with market access. Consider an "adaptation investment," $e_{j}$, defined as one needing an adapted contract (such as $Z$ ). By this definition, $e_{j}$ generates no direct benefits under $X$, but in default of renegotiation with $-j, j$ might still negotiate an adapted contract in the market. Accessing the market is usually more effective under $\Phi$ than under $X$, because enforcement of $X$ tends to deplete $j$ 's capacity for market trading. As a result, the default returns on most adaptation investments

\footnotetext{
${ }^{10} \mathrm{P}$ and A may trade in stage 1 , but I leave implicit the contract that enforces this trade.

${ }^{11}$ This self-investment case occurs when a specific investment, $e_{j}$, is directly compatible with $X$ by reducing $j$ 's cost of satisfying $X$ (e.g., IBM coaching) and/or raising $j$ 's benefit from $X$ (e.g., Amex learning to coordinate with IBM).
} 
are greater under $\Phi$ (through switching trade partner) than under $X$ (through side-trading). For an adaptation investment, $\psi_{e_{j}}$ represents the fractional returns on $e_{j}$ available through side-trading, so $\psi_{e_{j}}$ measures its "side-compatibility". Since the case with $\psi_{e_{j}}<\gamma_{e_{j}}$ is central to my paper, I now provide an explicit demonstration of how contract $X$ interferes with access to the market alternatives that could provide the needed adaptations. (This can be skipped at a first reading.)

Derivation of side-compatibility and generality. I treat in turn adaptations by a buyer and then adaptations by a seller, emphasizing how depleted trade capacity interferes with adaptations. When $j$ is the buyer, $j$ 's direct payoff under $X$ equals $j$ 's value of the basic service (or good) less the transfer to seller $-j$ imposed by contract $X$ in stage 3 . I denote this payoff by $v$ and normalize $j$ 's direct payoff under $\Phi$ to 0 . If $j$ and $-j$ negotiate the adapted contract $Z$, their joint surplus is $v+W_{j}\left(e_{j}\right)+W_{-j}\left(e_{-j}\right)-F_{1}$. In default of this renegotiation, $j$ must turn to an alternative seller such as $-j^{\prime}$.

When (under $\Phi$ ) $j$ switches to trade with $-j^{\prime},-j^{\prime}$ can provide the adapted trade to $j$ using a technology which $I$ denote by $T_{1}$. In contrast to $-j,-j^{\prime}$ has not sunk any investments specific to $j$, so technology $T_{1}$ involves additional fixed costs $F_{1}$ and may involve higher marginal costs of adaptation (relative to the technology used by $-j$ ). So I assume $j$ 's value from this trade takes the form, $v+\gamma_{1} W_{j}\left(e_{j}\right)-F_{1}$ for some $\gamma_{1} \in(0,1] .{ }^{12} I$ assume $v>F_{1}$ - the basic service is important enough to $j$ to justify the avoidable fixed cost $F_{1}$. So, absent renegotiation under $\Phi$, it is optimal (for all $e_{j}$ ) for $j$ to switch to buying the adapted trade from $-j^{\prime}$ through $T_{1}$. Hence $\gamma_{e_{j}}=\gamma_{1}>0$.

When side-trading (under $X$ ), $j$ 's value from trade with technology $T_{1}$ is only $\gamma_{1} W_{j}\left(e_{j}\right)-F_{1}$, because $j$ already has the basic service supplied by $-j$ under $X$ and $j$ only has a demand for one basic service. (More generally, $j$ 's demand for the basic trade is limited, so trade under $X$ depletes $j$ 's capacity for trade.) Assuming $\gamma_{1} W_{j}\left(e_{j}\right)<F_{1}$ for all $e_{j}$ (I generalize in the stochastic case below), it is never optimal to side-trade when $T_{1}$ is the only feasible technology. So $\psi_{e_{j}}=0<\gamma_{e_{j}}$.

Sometimes, the adapted trade can be separated into the basic trade (enforced by $X$ ) and a complementary adaptation. In other words, $-j^{\prime}$ can provide an adaptation service using an alternative, cheaper technology $T_{2}$ with fixed cost $F_{2}<F_{1}$. When the adaptation service is related to the basic service, there are economies of scope in having the same provider for both. ${ }^{13}$

\footnotetext{
${ }^{12}\left(1-\gamma_{1}\right) W_{j}\left(e_{j}\right)$ represents the increase in implementation costs; see Section 4 on the possibility of $\gamma_{1}>1$.

${ }^{13}$ Note that agency problems can generate economies of scope: e.g., $\psi_{e_{j}}$ is reduced if $-j$ is able to interfere with $-j$ 's activities under side-trading. Contractual terms that attempt to force $-j$ to cooperate with other providers are notoriously hard to enforce (see Lacity and Willcocks, 1998).
} 
So $T_{2}$ is less efficient: it generates a value $\gamma_{2} W_{j}\left(e_{j}\right)-F_{2}$ with $\gamma_{2}<\gamma_{1}$ and $F_{2}>v-F_{1}$. $T_{1}$ therefore remains optimal when $j$ switches supplier, but assuming $F_{1}-F_{2}>\left(\gamma_{1}-\gamma_{2}\right) W_{j}\left(e_{j}\right)$ for all $e_{j}, T_{2}$ 's lower fixed cost is attractive when $j$ engages in side-trading. In default of renegotiation, $j$ and $-j^{\prime}$ would use $T_{1}$ under $\Phi$ and $T_{2}$ under $X$. So $\gamma_{e_{j}}=\gamma_{1}$ (as before) and $\psi_{e_{j}}$ rises to $\gamma_{2}$. So separability raises $\psi_{e_{j}}$ but $\psi_{e_{j}}$ remains below $\gamma_{e_{j}}$, because $j$ 's limited demand dissuades $j$ from exploiting economies of scope (via technology $T_{1}$ ) when side-trading.

The result that $\gamma_{e_{j}}>\psi_{e_{j}}$ for adaptation investments is common to many generalizations of the trading technology, but the size of the difference $\gamma_{e_{j}}-\psi_{e_{j}}$ depends on contractual and organizational design (as well as technological separability and economies of scope). Endogeneity of $\gamma_{e_{j}}-\psi_{e_{j}}$ is important for the empirics of section 6. First, even when separation is technologically feasible, $\psi_{e_{j}}$ can be reduced to 0 by contractual terms, such as exclusivity restrictions included in $X$, that directly prevent $j$ from buying services from alternative sellers. Second, consider organization $j$ 's choice between buying from one or multiple sellers. If $j$ divides provision of the basic trade between $-j$ and $-j^{\prime}$ in stage 0 (e.g., through a pair of long-term contracts) then both $-j$ and $-j^{\prime}$ must sink fixed costs specific to $j$ of $F_{0}$ and $F_{0}^{\prime}$, respectively. This wastes the scope economy $F_{0}^{\prime}$ from using a single supplier and the gains from task specialization between the suppliers may be low. On the other hand, when $j$ makes adaptation investments, each of the two original suppliers has access to economies of scope in providing the adaptation. So the suppliers compete to provide j's adaptations. This raises the buyer's side-compatibility $\psi_{e_{j}}$. (See 6.3 and 6.5 for further analysis endogenizing these contract design and sourcing choices.)

Practitioners have long sought to predict where long-term contracting is likely to inhibit adaptation. It is therefore encouraging to find a direct link between my characterization and their practical advice. Practitioners distinguish adaptations that are 'substitute' trades from those that require 'related or unrelated, additional' trades. Their substitutes case corresponds to my case of non-separability ( $T_{2}$ is infeasible or does not exist) in which $\psi_{e_{j}}$ is usually zero. Their additional trades case corresponds to the case of separability. Also, the more the additional trade is related to the basic trade, the greater are the economies of scope in having the same provider for both. So $\psi_{e_{j}}$ is greater in these cases. By showing that contractual flexibility increases with side-compatibility $\psi_{e_{j}}$, my theory provides a foundation for the practitioner claims that contractual flexibility is lowest for adaptations requiring substitute trade and highest for adaptations that are additional and unrelated.

The case of adaptations by a seller is very similar to adaptations by a buyer: limited capacity for service production replaces limited service need as the constraint on side-trading. An exact parallel to the above buyer examples is feasible, but I treat the more common case 
where sellers can sell multiple basic or adapted trades. So when an adaptation is discovered, the seller wants to convert all its basic trades into adapted trades. If the seller $j$ 's longterm contracts demand a fraction $d$ of capacity and if adapted and basic services are equally demanding on trade capacity, ${ }^{14}$ then side-trading only permits $j$ to exploit a fraction $1-d$ of the feasible adaptation return. Hence, $\psi_{e_{j}}=1-d$, whereas short-term contracting - equivalent to $d=0$ - gives $\gamma_{e_{j}}=1>\psi_{e_{j}}$. I endogenize the capacity dedication choice, $d$, in the second empirical puzzle of section 6 (6.4).

Investment returns are often stochastic. Suppose $T_{1}$ is the only feasible technology and the adaptation value is $W_{j}\left(e_{j}\right)+y$ where $y$ is a random variable. The expected default return on $e_{j}$ under $\Phi$ is then $W_{j}\left(e_{j}\right) \operatorname{Pr}\left(v+W_{j}\left(e_{j}\right)+y-F_{1}>0\right)$ while the default return from side-trading under $X$ is $W_{j}\left(e_{j}\right) \operatorname{Pr}\left(W_{j}\left(e_{j}\right)+y-F_{1}>0\right)$. Clearly $\gamma_{e_{j}}=\operatorname{Pr}\left(v+W_{j}\left(e_{j}\right)+y-F_{1}>0\right)$ is still greater than $\psi_{e_{j}}=\operatorname{Pr}\left(W_{j}\left(e_{j}\right)+y-F_{1}>0\right)$. When $y$ can be large (e.g., if the buyer acquires another firm; see Lacity and Willcocks, 1998), both $\gamma_{e_{j}}$ and $\psi_{e_{j}}$ may be strictly increasing in $e_{j}$. This complicates the mathematics in optimizing contract length, but reiterates the paper's basic insight: contracts have a market-shielding effect that reduces adaptation incentives.

Investment categories. I categorize investments into two groups. An investment $e_{j}$ is type 1 (or contract-ophilic) if $\psi_{e_{j}}>\gamma_{e_{j}}$ and is type $\mathbf{2}$ (or contract-ophobic) if $\psi_{e_{j}}<\gamma_{e_{j}}$. (See section 4 for an extension.) This categorization generalizes the introductory distinction between investments for which the contract's protection effect dominates, or (respectively) is dominated by, its market-shielding effects. A self-investment (e.g., IBM's specific investment in cost-cutting that is protected by contract $X$ ) is a typical type 1 investment. An adaptation investment that is general but has limited side-compatibility (e.g., Amex's market research) is a typical type 2 investment.

In the model, each investor makes one investment of each type. (It is straightforward to generalize to any number of investments.) I denote $j$ 's type 1 and type 2 investments by $e_{j}$ and $i_{j}$, respectively. These investments generate additively separable returns $W_{j}\left(e_{j}\right)$ and $V_{j}\left(i_{j}\right)$ which I assume satisfy the standard concavity, monotonicity and Inada boundary conditions (guaranteeing interior investment choices).

Assumption 1. For $j \in\{P, A\}$,

$$
\begin{aligned}
& W_{j}^{\prime}\left(e_{j}\right)>0, W_{j}^{\prime \prime}\left(e_{j}\right)<0, \text { on } e_{j} \geq 0, \text { and } \lim _{e_{j} \rightarrow 0_{+}} W_{j}^{\prime}\left(e_{j}\right)=\infty, \lim _{e_{j} \rightarrow \infty} W_{j}^{\prime}\left(e_{j}\right)=0 ; \\
& V_{j}^{\prime}\left(i_{j}\right)>0, V_{j}^{\prime \prime}\left(i_{j}\right)<0, \text { on } i_{j} \geq 0, \text { and } \lim _{i_{j} \rightarrow 0_{+}} V_{j}^{\prime}\left(i_{j}\right)=\infty, \lim _{i_{j} \rightarrow \infty} V_{j}^{\prime}\left(i_{j}\right)=0 .
\end{aligned}
$$

\footnotetext{
${ }^{14}$ Adaptation might need additional capacity, e.g., $j$ might have just enough capacity to sell the basic service and one adaptation service. Then $j$ can sell an adaptation service to $-j^{\prime}$ alongside selling the basic service to $-j$, but this forfeits the economies of scope. So $\psi_{e_{j}}>0$ but remains less than $\gamma_{e_{j}}$.
} 
For sections 2 and 3 only, I also restrict the parameters $\gamma$ and $\psi$ to the unit interval, $[0,1]$.

Assumption 2. For each investment, $\gamma, \psi$ lie in $[0,1]$.

In the base case, all payoffs are additively separable in costs, benefits and transfers across time. $\mathrm{P}$ and $\mathrm{A}$ are risk-neutral ${ }^{15}$ and face no wealth constraints. Investment costs and trade payoffs are in money metric units and I normalize to the case with no time-discounting. So P and A's overall objectives are given by the utility functions, $U_{j} \equiv u_{j}-e_{j}-i_{j}+T_{j}$ where $u_{j}$ denotes the stage 3 trade payoffs and $T_{j}$ is the net additional transfer from $-j$ to $j,{ }^{16}$

$$
u_{j} \equiv\left\{\begin{array}{l}
\gamma_{e_{j}} \cdot W_{j}\left(e_{j}\right)+\gamma_{i_{j}} \cdot V_{j}\left(i_{j}\right), \text { if } \phi, \phi^{\prime} \\
\psi_{e_{j}} \cdot W_{j}\left(e_{j}\right)+\psi_{i_{j}} \cdot V_{j}\left(i_{j}\right), \text { if } x, x^{\prime} \\
W_{j}\left(e_{j}\right)+V_{j}\left(i_{j}\right), \text { under optimal trading }
\end{array}\right.
$$

Renegotiation. $\mathrm{P}$ and $\mathrm{A}$ always have symmetric information and I assume that stage 3 renegotiation leads to a fixed and equal split of any negotiation surplus over the default outcome determined by $\mathrm{P}$ and A's stage 0 contract; see section 4 for a generalization. I sketch the timing for this section in Figure 1.

\begin{tabular}{|c|c|c|c|}
\hline Stage 0 & Stage 1 & Stage 2 & Stage 3 \\
\hline \multirow{4}{*}{$\begin{array}{c}\text { Negotiate } \\
\text { X or } \Phi\end{array}$} & Invest & (Re)negotiate & Trade \\
\hline & $\mathrm{e}_{\mathrm{P}}, \mathrm{i}_{\mathrm{P}}$, and $\mathrm{e}_{\mathrm{A}}, \mathrm{i}_{\mathrm{A}}$ & $\mathrm{Z}, \mathrm{X}$ or $\Phi$ & \\
\hline & & $\&$ market trades & \\
\hline & \multicolumn{3}{|c|}{ Figure 1: Timeline for Base Model } \\
\hline
\end{tabular}

The first-best. In the first-best, $\mathrm{P}$ and $\mathrm{A}$ can fix $\mathbf{e}$ and $\mathbf{i}$ cooperatively at stage 0 . In stage 3 , the trade surplus is $u_{P}+u_{A}=\sum_{j=P, A}\left(W_{j}\left(e_{j}\right)+V_{j}\left(i_{j}\right)\right)$. So in stage 0 , they choose $\mathbf{e}$ and $\mathbf{i}$ to maximize their total surplus, ${ }^{17}$

$$
U_{P}(\mathbf{e}, \mathbf{i})+U_{A}(\mathbf{e}, \mathbf{i})=\sum_{j=P, A}\left[W_{j}\left(e_{j}\right)+V_{j}\left(i_{j}\right)-\left(e_{j}+i_{j}\right)\right]
$$

Assumption 1 ensures that the first order conditions are both necessary and sufficient, and

\footnotetext{
${ }^{15}$ I follow Goldberg and Erickson (1987) in ignoring risk. Recent evidence suggests risk-sharing often plays a limited role in contract design even in the classic case of small farmers (see Allen and Lueck, 1995, 1999).

${ }^{16}$ All statements hold "for $j=P, A$."

${ }^{17} T_{P}$ and $T_{A}$ (summing to 0 ) depend on relative bargaining power and participation constraints.
} 
give unique solutions to the first-best which I denote with a superscript*,

$$
\begin{array}{r}
V_{j}^{\prime}\left(i_{j}^{*}\right)-1=0 \\
W_{j}^{\prime}\left(e_{j}^{*}\right)-1=0
\end{array}
$$

In the second-best equilibrium, $\mathrm{P}$ and $\mathrm{A}$ choose $\mathbf{e}$ and $\mathbf{i}$ non-cooperatively, because these investments, their costs, and their resulting payoffs $\mathbf{u}$, are all non-verifiable (e.g., outsiders cannot measure the quality or cost of IBM's coaching investments). I therefore compare the Subgame Perfect Equilibria from alternative feasible stage 0 contracts to derive the optimal contract. I begin (in 2.1 and 2.2) with the two extreme contracts where $\mathrm{P}$ and A choose either $X$ or $\Phi$ at stage 0 . Superscripts ${ }^{L T C}$ and $S T C$ indicate the equilibrium values from long-term contracting (choosing $X$ at stage 0 ) and short-term contracting (choosing $\Phi$ at stage 0 ), respectively. I then treat the general case in 2.3 ; those familiar with incomplete contract theory can jump straight to 2.3 .

\subsection{Equilibrium with long-term contracting}

When $\mathrm{P}$ and $\mathrm{A}$ agree on $X$ at stage 0 , their default payoffs in stage 2 renegotiation are given by the expression, $\psi_{e_{j}} \cdot W_{j}\left(e_{j}\right)+\psi_{i_{j}} \cdot V_{j}\left(i_{j}\right)$. The total gain available on renegotiation is therefore,

$$
\sum_{j=P, A}\left[\left(1-\psi_{e_{j}}\right) \cdot W_{j}\left(e_{j}\right)+\left(1-\psi_{i_{j}}\right) \cdot V_{j}\left(i_{j}\right)\right]
$$

$\mathrm{P}$ and $\mathrm{A}$ each get their default payoffs plus half of these renegotiation gains, so after making investments $\mathbf{e}$ and $\mathbf{i}$, their expected payoffs from stage 2 onwards are given by,

$$
\frac{1}{2}\left(1+\psi_{e_{j}}\right) W_{j}\left(e_{j}\right)+\frac{1}{2}\left(1+\psi_{i_{j}}\right) V_{j}\left(i_{j}\right)+K\left(e_{-j}, i_{-j}\right)
$$

where $K\left(e_{-j}, i_{-j}\right) \equiv \frac{1}{2}\left[\left(1-\psi_{e_{-j}}\right) \cdot W_{-j}+\left(1-\psi_{i_{-j}}\right) \cdot V_{-j}\right]$. I solve for the Subgame Perfect Equilibrium using backward induction. Party $j$ invests to maximize this expected return less its investment cost, $e_{j}+i_{j}$. Since $K(\cdot)$ is independent of $e_{j}$ and $i_{j}, j$ 's problem is,

$$
\max _{e_{j}, i_{j}}\left(\frac{1}{2}\left(1+\psi_{e_{j}}\right) W_{j}\left(e_{j}\right)+\frac{1}{2}\left(1+\psi_{i_{j}}\right) V_{j}\left(i_{j}\right)-\left(e_{j}+i_{j}\right)\right)
$$

The first order conditions are again necessary and sufficient,

$$
\begin{aligned}
\frac{1}{2}\left(1+\psi_{e_{j}}\right) W_{j}^{\prime}\left(e_{j}\right)-1 & =0 \\
\frac{1}{2}\left(1+\psi_{i_{j}}\right) V_{j}^{\prime}\left(i_{j}\right)-1 & =0
\end{aligned}
$$


When $\psi=1$, these conditions replicate equation (1) and give the first-best, but for $\psi<1$, the concavity of $W$ and $V$ implies underinvestment. Investor $j$ 's investments increase with $j$ 's share of default returns, which increase with the compatibility parameters, $\psi_{e_{j}}$ and $\psi_{i_{j}}$; long-term contracting protects investments to the extent that they are directly compatible or side-compatible with the contract. The general intuition is familiar: a higher investment return in the default outcome reduces dependence on negotiating with the specific trading partner. The investor therefore loses a smaller share of investment returns in renegotiation, and better internalizes the investment.

Proposition 1. $e_{j}^{L T C}$ rises with $\psi_{e_{j}}$ and $i_{j}^{L T C}$ rises with $\psi_{i_{j}}$. Assumption 2 implies underinvestment in $i_{P}$ and $i_{A}$ and weak underinvestment in $e_{P}$ and $e_{A}: i_{j}^{L T C}<i_{j}^{*}$ and $e_{j}^{L T C} \leq e_{j}^{*}$ with equality only when $\psi_{e_{j}}=1$.

\subsection{Equilibrium with short-term contracting}

When $\mathrm{P}$ and $\mathrm{A}$ choose $\Phi$ at stage 0 , their stage 2 default payoffs are given by the expression, $\gamma_{e_{j}} \cdot W_{j}\left(e_{j}\right)+\gamma_{i_{j}} \cdot V_{j}\left(i_{j}\right)$. By analogy with the long-term contracting case, the first order conditions are,

$$
\begin{aligned}
\frac{1}{2}\left(1+\gamma_{e_{j}}\right) W_{j}^{\prime}\left(e_{j}\right)-1 & =0 \\
\frac{1}{2}\left(1+\gamma_{i_{j}}\right) V_{j}^{\prime}\left(i_{j}\right)-1 & =0
\end{aligned}
$$

Investments now increase with $\gamma$ instead of $\psi$, and there is underinvestment when $\gamma<1$.

Proposition 2. $e_{j}^{S T C}$ rises with $\gamma_{e_{j}}$ and $i_{j}^{S T C}$ rises with $\gamma_{i_{j}}$. Assumption 2 implies underinvestment in $e_{P}$ and $e_{A}$ and weak underinvestment in $i_{P}$ and $i_{A}: e_{j}^{S T C}<e_{j}^{*}$ and $i_{j}^{S T C} \leq i_{j}^{*}$ with equality only when $\gamma_{i_{j}}=1$.

In words, short-term contracting allows market forces to motivate investments to the extent that they are general, but (by the classic holdup problem) specificity causes underinvestment. ${ }^{18}$

\subsection{Equilibrium with intermediate contract length}

In Section 5, contracts can extend over multiple trading periods, but even in the basic model, I can treat contract length as a continuous variable by allowing for stochastic enforcement. I

\footnotetext{
${ }^{18}$ The intuition again follows from asking whether an investor can appropriate investment returns without having to renegotiate. Under short-term contracting, the default returns are determined by the investor's market alternatives reflected in $\gamma$. The problem is that market forces do not motivate specific investments.
} 
let $\alpha$ denote the probability that $X$ is enforced (in default of renegotiation). With converse probability $1-\alpha, \mathrm{P}$ and $\mathrm{A}$ 's default contract is $\Phi$. I assume that $\mathrm{P}$ and $\mathrm{A}$ can choose any $\alpha \in[0,1]$ at stage 0 - for instance, by varying contractual ambiguity ${ }^{19}$ or breach damages (see 6.2). This generalizes the above analysis because $\alpha=0$ corresponds to short-term contracting $(S T C)$ and $\alpha=1$ corresponds to long-term contracting $(L T C)$. I refer to $\alpha$ as contract length - the contract enforces trade for on average $\alpha \cdot G$ time units where $G$, the time elapsing between stages 0 and 3 , is the common gestation period of the investments. The interpretation of $\alpha$ as a deterministic contract length is validated in the multi-period model of section 5.

The default payoffs are now convex combinations of those from $X$ and $\Phi$ with weights, $\alpha$ and $1-\alpha$, respectively. The first-order conditions are therefore,

$$
\begin{aligned}
\frac{1}{2}\left(1+\alpha \cdot \psi_{e_{j}}+(1-\alpha) \gamma_{e_{j}}\right) W_{j}^{\prime}\left(e_{j}\right) & =1 \\
\frac{1}{2}\left(1+\alpha \cdot \psi_{i_{j}}+(1-\alpha) \gamma_{i_{j}}\right) V_{j}^{\prime}\left(i_{j}\right) & =1
\end{aligned}
$$

This set of equations allows me to generalize the first two propositions and show how contract length affects investment incentives as a function of the sign and size of $\psi-\gamma$. Raising $\alpha$ shifts weight from $\gamma$ onto $\psi$. This raises $H \equiv 1+\alpha \cdot \psi+(1-\alpha) \gamma$ when $\psi>\gamma$, and lowers it when $\psi<\gamma$. Equations (2) then imply that increasing $\alpha$ increases $W_{j}^{\prime}\left(e_{j}\right)$ and decreases $V_{j}^{\prime}\left(i_{j}\right)$, so $e_{j}$ rises and $i_{j}$ falls (as $W$ and $V$ are concave).

Proposition 3. (a) Increasing contract length raises type 1 and lowers type 2 investments. Mathematically, $\frac{d e_{j}(\alpha)}{d \alpha}>0, \frac{d i_{j}(\alpha)}{d \alpha}<0$. (b) Each investment rises with $\gamma$ (strictly if $\alpha<1$ ) and with $\psi$ (strictly if $\alpha>0$ ). (c) With Assumption 2, underinvestment is the only possible inefficiency.

$$
e_{j}^{S T C}<e_{j}(\alpha)<e_{j}^{L T C} \leq e_{j}^{*} \text { and } i_{j}^{L T C}<i_{j}(\alpha)<i_{j}^{S T C} \leq i_{j}^{*} \text { for all } \alpha \in(0,1)
$$

This captures the key tradeoff between increasing contract length to protect type 1 investments and reducing contract length so that market forces can better motivate type 2 investments. Type 1 investments, $e_{P}$ and $e_{A}$, are specific but contract-compatible $(\gamma<\psi)$ so the contract protects them better than do market forces. Type 2 investments, $i_{P}$ and $i_{A}$, are general and contract-incompatible $(\gamma>\psi)$ so for them, market forces are better than the long-term contract (with its side-compatible market forces). In the next section, I predict contract length by trading off contractual protection of e against its cost in shielding out contract-incompatible market forces that reward $\mathbf{i}$.

\footnotetext{
${ }^{19} \mathrm{I}$ can redefine $\alpha$ to be $\mathrm{P}$ and A's prior estimate of whether stage 3 trade will be induced.
} 


\section{Optimal Contract Length in the Basic Model}

$\mathrm{P}$ and $\mathrm{A}$ choose contract length at stage 0 . In this section, I show how optimal length is determined by the relative importance of different investments and the effectiveness and compatibility of contracts and market forces. In stage 0 negotiations, $\mathrm{P}$ and $\mathrm{A}$ can use up-front transfers to share any gains from a surplus increasing contract. So they choose $\alpha$ to maximize their total surplus, subject (unlike in the first-best) to the "incentive compatibility" conditions (2) on e and i. I denote the unique solutions of (2) by $e_{j}=e_{j}(\alpha)$ and $i_{j}=i_{j}(\alpha)$. So P and A's problem is,

$$
\max _{\alpha} \sum_{j=P, A}\left(W_{j}\left(e_{j}(\alpha)\right)+V_{j}\left(i_{j}(\alpha)\right)-\left(e_{j}(\alpha)+i_{j}(\alpha)\right)\right)
$$

Propositions 1-3 show that underinvestment is the only efficiency problem in the basic model. Proposition 3 also shows how to motivate more investment: increase $\alpha$ to improve type 1 investments, e, and decrease $\alpha$ to improve type 2 investments, i. Intuition therefore suggests that $\alpha$ should increase with the importance of $e_{P}$ and $e_{A}$ relative to $i_{P}$ and $i_{A}$. To investigate formally, I scale up the payoff impact of investments $e_{j}, i_{j}$ by the importance parameters, $E_{j}$, $I_{j}>0$ - i.e., I replace $e_{j}$ and $W_{j}\left(e_{j}\right)$ by $E_{j} e_{j}$ and $E_{j} \cdot W_{j}\left(e_{j}\right)$ and I replace $i_{j}$ and $V_{j}\left(i_{j}\right)$ by $I_{j} i_{j}$ and $I_{j} \cdot V_{j}\left(i_{j}\right)$. Notice that this rescaling does not change the first-order conditions for $e$ and $i$, but it does change the importance of having $e$ and $i$ close to their first-best levels (because the surplus loss from underinvestment is increasing in $E$ and $I$, respectively). The intuitive idea follows from solving $\mathrm{P}$ and A's rescaled problem,

$$
\max _{\alpha} \sum_{j=P, A}\left[E_{j} W_{j}\left(e_{j}(\alpha)\right)+I_{j} V_{j}\left(i_{j}(\alpha)\right)-\left(E_{j} e_{j}(\alpha)+I_{j} i_{j}(\alpha)\right)\right]
$$

Proposition 4a. Assuming the maximand of (4a) is concave (see appendix for sufficient conditions), the optimal contract length increases with the importance of investments of type 1, and decreases with importance of type 2's: $\alpha(\mathbf{E}, \mathbf{I})$ has $\frac{\partial \alpha}{\partial E_{j}}>0$ and $\frac{\partial \alpha}{\partial I_{j}}<0$.

This result is consistent with empirical evidence (see e.g., Brickley et al., 2003) on the positive correlation between contract length and the importance of non-contractible specific investments, $E_{A}$. Empiricists use the size of contractible specific investments as a proxy for the importance of non-contractible specific investments $\left(E_{A}\right)$. This proxy is imperfect but reasonable, because the two types of investment are strongly complementary. For instance, when IT outsourcing deals involve a significant (contractible) transfer of workers and assets from client to vendor, the complementary investments in retraining and reorganization are 
largely specific and non-contractible (as in the above IBM example). Furthermore, if the return on training per worker is independent of the transfer size (number of workers transferred), the total training investment and its return can be written as $E e$ and $E \cdot W(e)$; the rescaling exercise then exactly captures variation in transfer size. Using transfer size as a proxy, proposition 4 readily explains why almost all the longer IT contracts (those over 5 years long) occur in these "merger and acquisition" type deals.

An alternative comparative static exercise is to vary the productivity of an investment, so that $e_{j}$ generates a return $\hat{E}_{j} \cdot W_{j}\left(e_{j}\right)$ and similarly for $i_{j}$ with productivity parameter $\hat{I}_{j}$. This changes the first-order conditions to,

$$
\begin{aligned}
\frac{1}{2} H\left(\alpha ; \psi_{e_{j}}, \gamma_{e_{j}}\right) \hat{E}_{j} \cdot W_{j}^{\prime}\left(e_{j}\right) & =1 \\
\frac{1}{2} H\left(\alpha ; \psi_{i_{j}}, \gamma_{i_{j}}\right) \hat{I}_{j} \cdot V_{j}^{\prime}\left(i_{j}\right) & =1 \\
\text { where } H(\alpha ; \psi, \gamma) & \equiv(1+\alpha \cdot \psi+(1-\alpha) \gamma)
\end{aligned}
$$

$P$ and A's problem is now,

$$
\max _{\alpha} \sum_{j=P, A}\left(\hat{E}_{j} \cdot W_{j}\left(e_{j}\left(\alpha, \hat{E}_{j}\right)\right)+\hat{I}_{j} \cdot V_{j}\left(i_{j}\left(\alpha, \hat{I}_{j}\right)\right)-\left(e_{j}\left(\alpha, \hat{E}_{j}\right)+i_{j}\left(\alpha, \hat{I}_{j}\right)\right)\right)
$$

where $e_{j}\left(\alpha, \hat{E}_{j}\right)$ and $i_{j}\left(\alpha, \hat{I}_{j}\right)$ solve incentive compatibility conditions (5). Notice that the productivity parameters raise incentives to invest for fixed $\alpha$ (i.e., $\frac{\partial e_{j}\left(\alpha, \hat{E}_{j}\right)}{\partial \hat{E}_{j}}, \frac{\partial i_{j}\left(\alpha, \hat{I}_{j}\right)}{\partial \hat{I}_{j}}>0$ ). This effect countervails against the need to use $\alpha$ to further raise incentives (to exploit the productivity as in the intuition), so a clear result in this case requires a regularity condition (familiar from insurance contracting ${ }^{20}$ ),

Assumption 3. $W_{j}^{\prime}\left(e_{j}\right) W_{j}^{\prime \prime \prime}\left(e_{j}\right)>\left(W_{j}^{\prime \prime}\left(e_{j}\right)\right)^{2}$ and $V_{j}^{\prime}\left(i_{j}\right) V_{j}^{\prime \prime \prime}\left(i_{j}\right)>\left(V_{j}^{\prime \prime}\left(i_{j}\right)\right)^{2}, \forall e_{j}, i_{j}$.

Proposition 4b. Under assumption 3 (and the regularity condition of Proposition 4a), the optimal contract length increases with the productivity of investments of type 1, and decreases with productivity of type 2 investments: $\alpha(\hat{\mathbf{E}}, \hat{\mathbf{I}})$ has $\frac{\partial \alpha}{\partial \hat{E}_{j}}>0$ and $\frac{\partial \alpha}{\partial \hat{I}_{j}}<0$.

The effectiveness of markets and contracts (captured by $\boldsymbol{\gamma}$ and $\boldsymbol{\psi}$ ) also affects optimal contract length. There are two types of effect for any given investment. First, if $\psi$ and

\footnotetext{
${ }^{20}$ There is no precautionary saving interpretation here, but consider the sharp countervailing effect of a fixed cost self-investment: when the investment's importance generates incentives exceeding the fixed cost, $\alpha$ can be decreased. Assumptions 1 and 3 rule out generalized versions of this problem.
} 
$\gamma$ change so that $\delta \equiv \psi-\gamma$ rises while $H(\alpha ; \psi, \gamma) \equiv 1+\alpha \cdot \psi+(1-\alpha) \gamma$ is fixed, longterm contracting becomes more effective relative to the market forces freed by short-term contracting. This intuitively favors the use of longer contracts and should increase $\alpha$. I call this a substitution effect, because $\mathrm{P}$ and A substitute market forces for contract length according to their relative effectiveness as investment motivators. Second, an increase in $\gamma$ or $\psi$ directly raises the investment level for any given $\alpha$. This level effect is determined by changes in $H(\alpha)$ for fixed $\alpha$ and $\delta$. The level effect reduces the need to adjust $\alpha$ in favour of the investment, so the level effect on $\alpha$ is negative for type 1 investments and positive for type 2 investments.

Proposition 5. (Assume the regularity condition of Proposition 4a.) Contract length rises when type 1 investments become more specific ( $\gamma$ falls) and falls when type 2 investments become less contract-compatible ( $\psi$ falls). In general: Changes that increase $\delta=\psi-\gamma$ have a positive "substitution effect:" $\left.\frac{\partial \alpha(\boldsymbol{\gamma}, \boldsymbol{\psi})}{\partial \delta}\right|_{H=\hat{H}}>0$; Changes that increase $H(\alpha ; \psi, \gamma)$ have a "level" effect that is negative for type 1 , but positive for type 2, investments: $\left.\frac{\partial \alpha(\boldsymbol{\gamma}, \boldsymbol{\psi})}{\partial H}\right|_{\delta=\hat{\delta}} \stackrel{\text { sign }}{=}-\hat{\delta}$.

I use two direct corollaries in section 6 . First, contract length rises with $\psi$ for type 2 investments, so raising side-compatibility of an adaptation investment raises optimal contract length. ${ }^{21}$ Given that side-compatibility tends to be higher in multi-sourcing, this generates a tendency for longer contracts in multi-vendor situations. Second, contract length rises when market alternatives fall, because this makes investments more specific, i.e., $\gamma$ falls. This claim, famously supported by Joskow (1987) and others, is clearly valid for type 1 investments. My model shows that there is a complication, because the level effect when type 2 investments become more specific could motivate shorter contracts. However, the substitution effects are positive for all investments, so this effect will only dominate in special cases. Furthermore, some investments could switch from type 2 to type 1, raising the relative importance of type 1 investments and inducing longer contracts by proposition 4 .

\section{Cross Effects, Waste and Bargaining Asymmetry}

This section extends the model to allow for investment externalities, wasteful investment and bargaining asymmetries. A cross effect is an investment externality that occurs under the basic contract $X$ : the basic contract induces a (non-contractible) quality of trade that depends on prior investment by the trading partner. ${ }^{22}$ Cross effects may be negative. For instance,

\footnotetext{
${ }^{21}$ This generalizes to both investment types if level effects are limited (as when $\alpha=0$ ).

${ }^{22}$ Recall the introductory example where IBM's storage efficiency raises Amex's trade value under their payas-you-use contract. A fixed price contract prevents this cross effect, but then Amex's server needs have a
} 
IBM might develop a way to cut its cost (of satisfying the basic contract) at some expense to quality (as occurs under privatization in Hart et al., 1997). I define a cross-general effect as an investment externality occurring under $\Phi$. This occurs when one party's investment improves the other party's market alternatives under $\Phi$. For instance, Amex might learn technical or marketing knowledge from watching IBM invest in their joint trade. ${ }^{23}$ To complete the picture, I allow for negative cross-general effects where an investment harms the trade partner's market reputation.

IBM's private return on a negative cross-investment exceeds the social return, so I allow for $\psi>1$. This case also occurs for specific investments if separate trading is sometimes optimal. Similarly, $\gamma>1$ when investments (e.g., in advertising or search) generate alternatives that are mostly used as threat points. To allow for pure threat point investments, I even consider investments that are entirely wasteful in that their social return is zero. (Such threats - e.g. to exploit a contractual loophole - are never implemented in equilibrium.)

To extend the model, I now allow $j$ 's investment, $e_{j}$ to raise $-j$ 's payoff by $\psi_{e_{j}}^{\text {cross }} \cdot W_{j}\left(e_{j}\right)$ under $X$ (the cross effect), and by $\gamma_{e_{j}}^{\text {cross }} \cdot W_{j}\left(e_{j}\right)$ under $\Phi$ (the cross-general effect). I also allow $e_{j}$ to be a wasteful investment by removing the additive $W_{j}\left(e_{j}\right)$ term from the trade surplus under $Z{ }^{24}$ Similarly, for $i_{j}$. The impact of $j$ 's positive cross effects is to reduce $j$ 's payoff from renegotiation, because $-j$ 's default payoff is increased. The first order conditions (5) are unchanged except that (a) $\psi$ and $\gamma$ are replaced by $\bar{\psi} \equiv \psi-\psi^{\text {cross }}$ and $\bar{\gamma} \equiv \gamma-\gamma^{\text {cross }}$, and (b) in the case of wasteful investments, $H(\alpha ; \psi, \gamma)=1+\alpha \cdot \psi+(1-\alpha) \gamma$ is replaced by $H(\alpha ; \bar{\psi}, \bar{\gamma})-1=\alpha \cdot \bar{\psi}+(1-\alpha) \bar{\gamma}$

The implications of the cross effects are immediate corollaries of propositions 1 to 5 because all these results continue to hold after substituting $\bar{\psi}$ and $\bar{\gamma}$ in place of $\psi$ and $\gamma$ (see below on the case where $\bar{\psi}$ or $\bar{\gamma} \notin[0,1])$. The cross effects simply countervail against the corresponding self effects. In particular, an investment increases with contract length if and only if $\psi-\psi^{\text {cross }}>$ $\gamma-\gamma^{\text {cross }}$. So the natural extension of the type 1 investment is defined by $\bar{\delta} \equiv \bar{\psi}-\bar{\gamma}>0$ while type 2 investments are defined by $\bar{\delta}<0$.

A pure cross-investment is one for which $\psi^{\text {cross }}>0$, while the other parameters are zero. This is a type 2 investment because $\bar{\delta}=-\psi^{\text {cross }}<0$. So cross-investments fall with contract length $\alpha$ even though there cannot be any market-shielding if $\gamma=0$. Instead, the longterm contract is costly (as in Che and Hausch, 1999), because it increases the investment's

cross-effect on IBM (see also 6.1).

${ }^{23}$ Similarly, suppliers may learn from their buyers. E.g., Solectron learned how to make own-brand products after working for IBM, HP and Mitsubishi (see Arruñada and Vazquez, 2004, and Lee and Hoyt, 2001).

${ }^{24}$ If $e_{j}$ actually reduces this social return, the effects are simply more pronounced. 
externality and therefore lowers the investor's incentive. A corollary of the extended version of proposition 4 is that contracts should become shorter as cross-investments become more important. ${ }^{25}$

A pure cross-general investment is one for which only $\gamma^{\text {cross }}>0$. This is a type 1 investment since $\bar{\delta}=\gamma^{\text {cross }}>0$, so it rises with $\alpha$. The contract helps because it shields out the market externality. The extension of proposition 4 predicts longer contracts when cross-general effects are important. A contract imposing exclusivity alone may (if legal) be more effective in preventing cross-general externalities (see Segal and Whinston, 2000), but performance contracting is often preferable since this also motivates self-investments and side-compatible adaptations.

Asymmetries in bargaining do not change the nature of these effects, but they do change the relative importance of cross and self effects, because self effects lead to a benefit without need for bargaining power, while cross effects only matter through traders' renegotiation shares. If $j$ now wins a share $\theta_{j} \in[0,1]$ of the renegotiation returns, $j$ 's incentive conditions are as in (5) except that (a) $\bar{\psi}$ and $\bar{\gamma}$ replaced by $\psi(\theta) \equiv(1-\theta) \psi-\theta \psi^{\text {cross }}$ and $\gamma(\theta) \equiv(1-\theta) \gamma-\theta \gamma^{\text {cross }}$ and (b) $H(\alpha ; \psi, \gamma)$ is replaced by $H(\alpha ; \psi, \gamma, \theta) \equiv[2 \theta+\alpha \cdot \psi(\theta)+(1-\alpha) \gamma(\theta)]$. Again the results extend in straightforward fashion. An investment is now type 1 if $\delta(\theta)>0$ where $\delta(\theta) \equiv \psi(\theta)-\gamma(\theta)$, and type 2 if $\delta(\theta)<0$. I now return to the case with $\theta=\frac{1}{2}$ for expositional fluidity.

When an investment is wasteful, the impact of contract length is determined by its parameters $\bar{\psi}$ and $\bar{\gamma}$ exactly as for productive investments apart from the level effect implicit in replacing the factor $H$ by $H-1$ ( $H-2 \theta$ in the general case). However, the maximand (3) only includes the subtraction of the investment cost, since it has no social return. So $\mathrm{P}$ and A aim to minimize the cost, and the message of proposition 4 is exactly inverted. I first prove this in proposition 6 a by varying the importance (scale), $K_{j}$, of a wasteful investment, $k_{j}$ that costs $K_{j} k_{j}$ and generates private returns $K_{j} \cdot B_{j}\left(k_{j}\right)$ where $B_{j}(\cdot)$ satisfies the above regularity conditions. Then in proposition $6 \mathrm{~b}, \mathrm{I}$ prove the same result holds for increases in the productivity $\hat{K}_{j}$ of a wasteful investment $k_{j}$, that costs $k_{j}$ and generates private returns of $\hat{K}_{j} B_{j}\left(k_{j}\right)$. This second result requires that $B_{j}(\cdot)$ satisfy assumption 3 , because of the countervailing effect described in proposition $4 \mathrm{~b}$ above. (Interestingly, assumption 3 is also a sufficient condition

\footnotetext{
${ }^{25}$ There is one complication. Intermediate breach penalties might allow the non-investing trader to credibly threaten termination after low cross-investment. Che and Hausch (1999) argue that such option schemes do not work (given renegotiation), because the trader would threaten to terminate even after high cross-investment. Ellman (2006) shows that, absent reputational mechanisms, this critique is invalid when options are decided by a trading decision (see also Watson, 2005). However, option schemes have $\alpha<1$ in generic stochastic settings, so there is still a tendency towards shorter contracts.
} 
for regularity (concavity) of the overall maximization problem.)

Proposition 6a. Optimal contract length is decreasing in the importance of any wasteful type 1 investment with return function satisfying assumption 1 and regularity of the overall optimization - assumption 3 is a sufficient condition. By contrast, optimal contract length increases with the importance of wasteful type 2 investments: $\frac{d \alpha}{d K_{j}}<0$ if and only if $\bar{\delta}_{j}>0$.

Proposition 6b. If a wasteful investment's return function satisfies assumptions 1 and 3, optimal contract length is decreasing in the investment' productivity for type 1 investments and increasing in productivity for type 2 investments: $\frac{d \alpha}{d \hat{K}_{j}}<0$ if and only if $\bar{\delta}_{j}>0$.

When $\bar{\psi}>1$ (either from negative cross-investment effects or from $\psi>1$ or both), there is a risk of over-investment - for any $\alpha>\frac{1-\bar{\gamma}}{\bar{\psi}-\bar{\gamma}}$. So, for high $\alpha$, changing the productivity (importance) of this investment has the same effect as if the investment were wasteful, while for low $\alpha$, the implications are as in proposition 4. Similarly, when $\bar{\gamma}>1$, there is a risk of over-investment for low values of $\alpha .^{26}$

In conclusion, the impact of cross effects $\left(\psi^{\text {cross }}\right.$ and $\left.\gamma^{\text {cross }}\right)$ is the inverse of the corresponding self effects $(\psi$ and $\gamma$ ) and the impact of importance on contract length is inverted for an investment that is wasteful or excessive. When traders are inexperienced or uncertainty and complexity are high, it is harder to write contracts that pin down quality, so there is a greater risk of cross effects. This section helps explain why contracts are often short in such settings: contract length is reduced to better motivate cross-investments and to reduce over-investment in investments with negative cross effects. (A complementary effect of uncertainty is to increase the importance of adaptations. This can also explain the shorter contracts observed.)

\section{Temporal Extension}

This section analyzes multi-period extensions of the trading model. Stage 3 trading is spread over time ${ }^{27}$ and subdivided into $N$ discrete trade decisions, each lasting $l$ units of time. A simple long-term contract enforcing trade in the first $m \leq N$ substages has length $L=m \cdot l+G$ (where

\footnotetext{
${ }^{26}$ To complete the generalization, $\bar{\psi}$ and $\bar{\gamma}$ might also be negative, but this has no special effect other than possible corner solutions at zero investment.

${ }^{27}$ Trade is often spread over time because production is time-intensive, being limited by capacity and procedural constraints. Also demands are spread over time (and storage is impossible for services like IT). See 6.1 on endogenizing trade intensity.
} 
as defined above, $G$ is the time elapsing between stages 0 and 3 ). In this section, I analyze why optimal contracts often take this form and show that the tradeoff from varying $L$ is then identical to that of varying $\alpha$ in the basic model: Increasing $L$ protects self-investments for longer, but shields out for longer market forces that protect adaptations.

I maintain the standard assumption that parties can always renegotiate, so I need $N$ renegotiation stages - one before each trading decision. In the simplest extension, there is only one investment stage and no history dependence within the extended trading interval, so the trade payoffs in each substage are scalar multiples of the trade payoffs from the basic model. The impact of stage 1 investments may vary with time, so I let the compatibility, generality and importance parameters depend on $n$. The overall game is as before except that stages 2 and 3 are replaced by their $N$-fold replication and the initial contract determines a probability $\alpha_{n}$ of trade enforcement via $X_{n}$ (equivalent to $X$ ) in each of the $n$ trade stages. The extended timing is therefore: (Stage 0) $\mathrm{P}$ and A negotiate $\left(\alpha_{n}\right)_{n=1}^{N}$ and lump-sum transfers; (Stage 1) P and A invest; [(Stage $2 n)$ Renegotiation over $X_{n}$; (Stage $\left.2 n+1\right) n$ 'th trading decisions $]_{n=1}^{n=N}$.

Given the absence of history-dependence within the subgame starting from stage $2,{ }^{28}$ the continuation payoffs equal the sum of the equilibrium payoffs from the $N$ paired stages $(2 n$ and $2 n+1)_{n=1}^{n=N}$. The first-order conditions therefore modify (5) into,

$$
\begin{aligned}
\left(\sum_{n=1}^{N} \frac{1}{2} H\left(\alpha_{n} ; \bar{\psi}_{e, j, n}, \bar{\gamma}_{e, j, n}\right) \cdot \hat{E}_{j, n}\right) \cdot W_{j}^{\prime}\left(e_{j}\right) & =1 \\
\left(\sum_{n=1}^{N} \frac{1}{2} H\left(\alpha_{n} ; \bar{\psi}_{i, j, n}, \bar{\gamma}_{i, j, n}\right) \cdot \hat{I}_{j, n}\right) \cdot V_{j}^{\prime}\left(i_{j}\right) & =1
\end{aligned}
$$

In the case of a time invariant technology, the summations in (6) simplify to $\frac{1}{2} H\left(\alpha ; \bar{\psi}_{i, j}, \bar{\gamma}_{i, j}\right) \cdot \hat{E}_{j}$ and $\frac{1}{2} H\left(\alpha ; \bar{\psi}_{i, j}, \bar{\gamma}_{i, j}\right) \cdot \hat{I}_{j}$, where $\alpha \equiv \frac{\Sigma_{n=1}^{N} \alpha_{n}}{N}$ and $\hat{E}_{j}=\sum_{n=1}^{N} \hat{E}_{j, n}\left(=N \cdot \hat{E}_{j, n}\right.$ for each $\left.n\right)$ and $\hat{I}_{j}=N \cdot \hat{I}_{j, n}$ (for all $n$ ). So contracts with the same $\alpha$ are equivalent in terms of incentive efficiency. In particular, the simple long-term contract of length $L=m \cdot l$ is defined by $\alpha_{n}=1_{\{n \leq m\}}$, so it is equivalent to $\alpha=\frac{m}{N}\left(=\frac{L-G}{L-G}\right.$ where $\bar{L}=N \cdot l$ is the maximal trade duration) and I can state,

Proposition 7. In the multi-period extension with time invariance, restricting to simple long-term contracts has no efficiency cost and propositions 1-6 all hold with $L$ replacing $\alpha$.

\footnotetext{
${ }^{28}$ Renegotiation and interdependence among the $\alpha_{n}$ could create history-dependence inside the subgame, but the game with independent $\alpha_{n}$ and renegotiation restricted to only adjusting the contract for the upcoming trading period has the same equilibria.
} 
Time-invariance is a special case. Allowing for variation in the productivity parameters $E$ and $I$ over time $n$ permits further predictions. First, if self-investments become redundant over time and/or adaptation investments become more important over time, simple contracts are uniquely optimal. The intuition is that simple contracts exploit contractual protection where most effective and least harmful (in terms of market-shielding), because they crowd trade enforcement into the earliest substages where $E_{j, n}$ is large relative to $I_{j, n} \cdot{ }^{29}$ Second, one can study varying gestation periods, by setting $G=0$ and defining $G_{e_{j}}=l \cdot \max \left\{n: E_{j, n}=0 \forall m \leq n\right\}$ (and $G_{i_{j}}$ similarly). Two implications are immediate. If contract length $L>0$, then $L$ should exceed $\min _{j} G_{e_{j}}$, because otherwise the contract has no protection benefit. ${ }^{30}$ This may help explain why agriculture contracts are longer in the case of fruit trees as shown in Bandiera's (2002) historical data. However, when $G_{e_{j}}$ gets too large, the market-shielding cost may be prohibitive and $L$ will fall back, as traders abandon the idea of protecting $e_{j}$. Further implications, depend on the time profiles of investment productivity and can be analyzed using the extended model.

A pair of arguably stronger reasons for the prevalence of simple contracts derive from plausible history dependence within the trade interval. Unless a contract is simple, it must involve at least one 'performance gap' during which the contract does not enforce joint trade. Switching to an alternative trade during such a gap is often not credible, because the trader would anticipate having to pay fixed costs of switching back to joint trade after the gap (in addition to fixed costs of switching to the alternative trade). ${ }^{31}$ This implies market-shielding even during the contractual gap, so there is no cost from filling in the gap with performance. Even when switching is credible during a gap (that is long enough to justify the fixed costs of switching) switching to an alternative partner for the main trade can reduce the marginal value of specific investments when returning to joint trade. For instance, switching may require reorganizations that interfere with the specific investments. This reduces the effectiveness (investment protection) of imposing performance after the gap. With these endogenous parameter shifts, avoiding performance gaps through simple contracts is optimal since it maximizes contract

\footnotetext{
${ }^{29}$ The general condition for unique optimality of simple contracts is that the importance of type 1 investments grow at a lower rate than for type 2's - i.e., $\varepsilon_{n} \equiv \frac{\hat{E}_{j, n+1}}{\hat{E}_{j, n}}<\iota_{n} \equiv \frac{\hat{I}_{j, n+1}}{\hat{I}_{j, n}}, \forall n, \forall j$. The proof is simple when $\gamma$ and $\psi$ are independent of $n$ : The summation terms in the first-order conditions become $\frac{1}{2} H\left(\sum_{n=1}^{N} \alpha_{n} \hat{E}_{j, n} ; \bar{\psi}_{e_{j}}, \bar{\gamma}_{e_{j}}\right)$ and $\frac{1}{2} H\left(\sum_{n=1}^{N} \alpha_{n} \hat{I}_{j, n} ; \bar{\psi}_{i_{j}}, \bar{\gamma}_{i_{j}}\right)$. Now suppose that $\alpha_{n+1}>0$ when $\alpha_{n}<1$. Decreasing $\alpha_{n+1}$ by (any feasible) $\eta>0$ and increasing $\alpha_{n}$ by $\iota_{n} \cdot \eta$ fixes the incentive on all type 2 investments and increases the incentives for all type 1 investments by $\left(\iota_{n}-\varepsilon_{n}\right) \frac{\eta}{2} \delta>0$. Hence $\hat{\alpha}_{n}<1 \Rightarrow \hat{\alpha}_{n+1}=0 \forall n \in\{1,2, \ldots, N\}$. Gaps are always avoided.

${ }^{30}$ If $\min _{j} G_{i_{j}}>0$ then there is no market-shielding cost for $L \in\left[0, \min _{j} G_{i_{j}}\right)$ so the precise claim is that $L$ should exceed $\min _{j} G_{e_{j}}$, if $L>\min _{j} G_{i_{j}}$.

${ }^{31}$ For side-compatible adaptations, alternative trade credibility is in fact higher during performance contracting.
} 
protection relative to market-shielding. ${ }^{32}$

My model could be extended in two directions. First, I have deferred a general analysis of settings with switching costs, because intermediate breach penalties can generate a rich multiplicity of equilibria. In this case, alternative trades become "outside options" (see Osborne and Rubinstein (1990)). If one applies the Outside Option Principle as in MacLeod and Malcomson (1993), my results apply unless one trader's outside option binds in which case the other trader gets the full share of renegotiation surplus. If only one trader makes relationshipspecific investments, the tradeoff between protection and market forces is escaped by giving an attractive breach option to the trader who only makes general investments.

Second, initial investments are often the most important - as with IBM's training investments - however, ongoing investments are also important, especially for adaptations. Introducing additional investment stages after stage 2 requires ongoing renegotiation in which the new contract at each stage should be designed to optimize incentives for the upcoming investment problem. My framework would then predict the length of each new contract, assuming intertemporal additivity for all investments. Guriev and Kvassov (2006) study precisely this problem in the case of a single investment, though without the market-shielding problem, and under the premise that renegotiation is exogenously costly. ${ }^{33}$

However, I suspect that these predictions are sensitive to the symmetric information assumption. For instance, the long fixed term in the IBM-Amex contract was mostly driven by the need to motivate early investments in reorganization and retraining. Introducing ongoing adaptation investments (or cross-investments), one might have expected renegotiation to a shorter contract once IBM's main transition costs had been sunk. This has not happened so far and such renegotiations are rare. I suggest two reasons. First, asymmetric information frustrates such renegotiation. When unable to fully observe IBM's training investments, Amex faces an adverse selection problem, because IBM is more willing to shorten the contract after weak training investments. Furthermore, renegotiation terms cannot depend fully on IBM's training investments, so IBM's incentives would suffer greatly. Second, the remaining length of

\footnotetext{
${ }^{32}$ I defer a general analysis of settings with switching costs, because intermediate breach penalties can generate a rich multiplicity of equilibria. Alternative trades become "outside options" (see Osborne and Rubinstein (1990)). If one applies the Outside Option Principle as in MacLeod and Malcomson (1993), my results apply unless one trader's outside option binds in which case the other trader gets the full share of renegotiation surplus. If only one trader makes relationship-specific investments, the tradeoff between protection and market forces is escaped by giving an attractive breach option to the trader who only makes general investments.

${ }^{33}$ They show how contracts specifying a minimum advance notice for termination provide ongoing investment incentives without need for continuous renegotiation. Adding my market-shielding effect to their problem would lead to shorter advance notice requirements. Che and Sákovicz (2004) also allow for ongoing investment, but assume trade can only occur once and focus on an infinite time horizon.
} 
the contract and size of breach penalties fall automatically with time, so adaptation incentives automatically increase over time.

I conclude this section with a brief comment on measuring contract length. This is nontrivial when breach is stochastic (as in 6.2). I defined the "effective" length of a contract as the amount of time over which a single performance contract would induce trade in the absence of renegotiation. Through premature breach, this can be lower than the length reported in the contract (called the "nominal" length in Aghion and Bolton, 1987). Nonetheless, reported nominal length ( 7 years in the case of IBM-Amex) is a good proxy for effective length, because breach penalties often fall sharply to zero at the end of the reported period. ${ }^{34}$

\section{Applications}

This section describes how contractual features (quantity decisions, various types of menu, contractual restrictions, breach damages and informal enforcement) and trading choices (multisourcing, capacity dedication and selective outsourcing) affect the compatibility parameter $\psi$ and market-shielding. In particular, the last three subsections analyze the empirical puzzles from the introduction. My examples remain focused on IT outsourcing and I refer to the Center for Organizations Research and Innovation (CORI) for detailed IT outsourcing contracts: Cobancorp-EDS (1995-2002), UHS-Unisys (1996-2005), GM-EDS (1996-2006), Tri City BankM\&I Data Services (1998-2006). However, I also use data on the multi-year contracts in contract manufacturing, input procurement and franchising.

\subsection{Contract Design}

Three minor extensions of the basic model greatly increase the realism. First, traders generally choose among many possible basic trades when writing their initial performance contract. The traders then optimally choose a contract with which valuable investments are highly compatible and undesirable investments have zero or low compatibility. ${ }^{35}$ It is instructive to revisit Edlin and Reichelstein's (1996) model of self-investments in which specific performance contracts with carefully chosen trade quantity can induce first-best investment incentives. Introducing adaptation investments into their model would prevent reaching the first-best, because raising trade quantity (or intensity) reduces side-compatibility (see model of the intensity variable denoted $d$ in section 2 and in 6.4 below). In the multi-period model laid out in section 5 , an

\footnotetext{
${ }^{34}$ For ever-green contracts, the length of the advance notice period is the key proxy, but the size of the penalty on giving notice is particularly important as the effective length is infinite if this penalty is too high.

${ }^{35}$ This statement applies with opposite signs for cross compatibility.
} 
extremely brief but intense contract could conceivably limit this market-shielding problem, but there is a major risk that such a contract would simply encourage wasteful investments that are only useful for producing at artificially high intensity.

Second, the long-term contract might include a trade menu from which at least one party (usually the client) can choose after investing. For instance, in IBM and Amex's "pay-as-youuse" contract, Amex owes less to IBM if it uses less server space. This raises side-compatibility for any Amex adaptation that affects its server space needs. However, flexibility must be limited to protect the seller's specific investments. Pricing is generally non-linear. For instance, the lion's share of Amex's service charge is effectively fixed. ${ }^{36}$

Third, the contractual menu might be determined over time through a set of modification procedures. Indeed, a large share of vendor compensation in the long-term contracts supporting "acquisition" deals (involving substantial restructuring as in Amex-IBM) comes in the form of a "revenue commitment" that fixes a minimal expenditure by the client on the vendor's services (sometimes, as a percentage of the client's IT expenditure - see GM-EDS, 1996). Revenue commitments give the client the flexibility to choose what to buy, but this flexibility is only meaningful when optional items are reasonably priced. Arbitration and benchmarking procedures are therefore necessary. These procedures work well for minor modifications and easily priced 'new releases,' but there is a significant risk that the arbitrator (being imperfectly informed) specifies an excessive price on a non-standard adaptation or additional service. The vendor and client then engage in bilateral negotiations to find a mutually agreeable price. So the credibility of market threats again determines the degree of holdup. ${ }^{37}$ Any changes that require negotiation are equivalent to adaptations and my analysis continues to apply. ${ }^{38}$

Cost-plus contracts can be viewed as a menu contract in which they buyer can demand adaptations on the condition of paying the additional costs required by adaptation. When containing a minimal trade guarantee, such a contract is very similar to the revenue commitment contract. In ideal circumstances, this again resolves the holdup problems analyzed above.

\footnotetext{
${ }^{36}$ Koch (2003) criticizes IBM's exaggeration in claiming to have invented a fully flexible "e-business utility" model. Goldberg and Erickson (1987) is a classic reference on non-linearity in long-term contracting.

${ }^{37}$ Arbitrators may require demonstration of market alternatives when seeking benchmark prices. The credibility of side-trading then affects the benchmarked price fixed by this "market test." See e.g., additional services and market tests in GM-EDS's $\$ 40$ bn contract.

${ }^{38}$ Relatedly, some contracts fix an annual limit on "system enhancements" that the client can demand at a predetermined total price, but again the arbitrator's ignorance may lead to over-estimates of the work hours required for a given enhancement. Flexibility is further limited when the client exceeds the 'total work hours' as occurred to the UK Inland Revenue-Accenture contract after legislators introduced "stakeholder pensions" in 1998 and quarterly tax reporting for corporations in 1999 (see NAO, 2001).
} 
However, the problem is as before: measuring adaptation costs is often too difficult. ${ }^{39}$

\subsection{Contract Enforcement and Breach Damages}

As just noted, the principal contract enforcement problem underlying my main result is the non-verifiability of adaptation costs. Since verifiability is also a problem for informal enforcement mechanisms involving third parties, my results continue to apply in settings where trade agreements are enforced by group or market reputations. However, if the trading relationship were governed by bilateral self-enforcement (also called relational contracting), these informational constraints would be avoided. Unfortunately, in settings where large specific investments are sunk at the start of the relationship and pay off over a period of many years, repetition within the same relationship is unlikely. So self-enforcement of these investments is not usually feasible. By contrast, adaptation investments and returns are often more frequently repeated, so reputational mechanisms should favour longer contracts. ${ }^{40}$

My sharp non-verifiability assumptions also ruled out more subtle breach penalties such as reliance and expectation damage measures as alternatives to liquidated damages. Relaxing these assumptions reduces the difficulty of motivating investments, but with imperfect measurement of the potential costs and benefits from adaptation, market forces and side-compatibility still matter. Even without relaxing the assumptions, there is one further issue: the optimal contract design may involve intermediate liquidated damages.

In section 4, I explained how intermediate damages enable option contracts to induce breach threats after low cross-investment. I now show how intermediate damages can make breach credibility contingent on the stochastic value of adaptation investments. For instance, after Halifax acquired the Bank of Scotland (BoS) in 2002, its gain from substituting BoS's centralized IT infrastructure with a more decentralized system exceeded the breach damages in BoS's outsourcing contracts with IBM and Xansa (see Computer Weekly, 2002). So the acquisition induced breach and the marginal returns on acquisition investments were high, because the breach penalty was fairly low. In terms of the model, the moderate breach penalties

\footnotetext{
${ }^{39} \mathrm{My}$ strict assumption that costs are non-verifiable rules out cost-plus contracting, but in settings where many similar traders could gain from long-term contracting and good incentives to adapt, the traders might pay to create a specialist agency that would build a capability and reputation for verifying adaptation costs. In these settings, contracts could be longer without suffering from serious rigidities. (Of course, if the agency could also verify investments, long-term contracts would not be needed either.)

${ }^{40}$ Specific assumptions about renegotiation are also important. For instance, they determine whether longterm contracts can credibly increase mutual punishment in support of self-enforcement. (For evidence that formality does not imply deep distrust, notice that the litigation between Xerox and EDS did not prevent them from later extending their trading relationship - DiSabatino, 2001).
} 
raised side-compatibility without an excessive fall in protection of self-investments. In general, it is optimal to make breach credible in states where the marginal returns to adaptation investments are maximal, thereby exploiting market forces at their most powerful. Intermediate breach damages therefore dominate stochastic enforcement with high breach penalties, whenever the marginal and absolute returns on adaptations are positively correlated. ${ }^{41}$

\subsection{Multiple Vendors}

In 2003, Procter and Gamble (P\&G) decided against putting all its eggs in one basket, by outsourcing its IT to three key vendors: Hewlett-Packard, IBM and Jones, Lang \& Lasalle see Weiss and Perez (2003). A stylized analysis of this decision clarifies the flexibility advantage of the multi-vendor approach; see Currie (1998) for two related case studies. Each vendor had to sink fixed costs in learning about P\&G. Had P\&G instead outsourced to EDS in a one-stop contract, as initially planned, EDS would have reaped economies of scope by sinking one set, instead of three sets, of fixed learning costs. However, in addition to minor specialization gains, $\mathrm{P} \& \mathrm{G}$ benefits from the multiple sunk costs, because these three vendors create credible competition for many of the service adaptations that $\mathrm{P} \& \mathrm{G}$ may later discover (see model below). This increased competition allows P\&G to negotiate adaptations more cheaply and more reliably.

López and Ventura (2001) and González and López (2002) analyze outsourcing contracts in the electronics industry using primary source data from ANIEL. ${ }^{42}$ Their survey reports how many subcontractors are used by each manufacturer as well as the estimated length of written contracts. Having multiple subcontractors, or vendors, is a good proxy for the existence of competing providers. So, based on Joskow (1987) (see section 3 above), they expected a negative correlation with contract length. Instead, they found an insignificant positive correlation. I claim that the concept of side-compatibility can resolve this puzzle; ${ }^{43}$ Multi-sourcing increases side-compatibility and proposition 5 shows that optimal contract length should therefore increase. This counteracts the pressure to make contracts shorter. So it could explain the

\footnotetext{
${ }^{41}$ Of course, where possible, breach damages are directly contingent on events - e.g., mergers and acquisitions - where adaptations tend to be important. Similarly, because adaptations often become increasingly important over time, breach damages usually fall gradually over the duration of a contract.

${ }^{42}$ Asociación Nacional de Industrias Electrónicas y de Telecomunicaciones. Electronics outsourcing is a global phenonomenon: e.g., huge 3-year deals between IBM and Sanmina-SCI in 2002 and 2003, and Casio and Flextronics in 2002, and 5-year deals between HP and Solectron in 2003 and Avaya and Celestica in 2001.

${ }^{43}$ Errors in measurement and coding (of contract length) could also explain the insignificance, so further empirics is needed. For richer but sparser data with the same positive correlation, see Beulen and Ribbers' (2003) IT outsourcing case studies.
} 
empirical result, but to be thorough, I need to endogenize the sourcing decision. I do so now for a single buyer with two potential sellers.

I build on the simple technological setup described in the italicized derivation of sidecompatibility from section 2: I allow for exogenous variation in the size of the fixed startup costs and in the investment importance parameters, $I$ and $E$. Each of the two potential suppliers faces the same fixed cost $F$ of servicing the buyer's specific needs. So dual sourcing wastes a possible scope economy worth $F$. This may be partially compensated by specialization gains, $S$. So the technological advantage of single sourcing is $F-S .{ }^{44}$ Now for single sourcing, the supplier that is not selected in advance can still avoid sinking its fixed cost when an adapted service is discovered, so given $F>\gamma W(e)$, this supplier will not credibly compete for providing the adapted service and $\psi=0<\gamma \cdot{ }^{45}$

By contrast, under dual sourcing, the fixed costs of each supplier have already been sunk, so each supplier offers credible competition against the other. By construction, adaptation by the optimal supplier generates $W(e)$. To allow for gains from learning, I suppose the other provider generates $\gamma^{\prime} W(e)$ with $\gamma^{\prime} \geq \gamma$. If the buyer runs a sourcing auction, side-compatibility $\psi_{\text {dual }}$ is then equal to $\gamma^{\prime}$. The buyer's default adaptation returns are just as high as when the dual source contracts expire, since $\gamma_{\text {dual }}=\gamma^{\prime}$ too. So the adaptation cost from long-term contracting is now zero $\left(-\delta_{\text {dual }}=\gamma_{\text {dual }}-\psi_{\text {dual }}=0\right)$ and more generally is much lower than under single sourcing. ${ }^{46}$

So proposition 5 predicts that exogenously imposing dual sourcing will raise contract length. I now endogenize the sourcing decision. Up-front transfers (determined in the ex ante competition among suppliers) imply that the buyer chooses the sourcing strategy that maximises total surplus. So I simply compare the surpluses under dual and single sourcing. Dual sourcing wastes $F-S$ relative to single sourcing, but raises the equilibrium level of adaptation investments by an amount $\Delta e$. Since $\Delta e$ is increasing in contract length $\alpha,{ }^{47}$ I analyze the joint choice of sourcing and length.

I begin with the simple case where $F$ or $S$ varies for some exogenous technological reason. An increase in $F-S$ directly raises the probability of single sourcing and therefore (by reducing side-compatibility) lowers the expected contract length $\alpha$. Variation in $F-S$ therefore

\footnotetext{
${ }^{44}$ Positive $F-S$ is trivial: dual sourcing is then technologically and strategically (for investment incentives) optimal.

${ }^{45}$ This neglects the possibility of multiple trade technologies, but the analysis readily generalizes since the fixed cost sunk under dual sourcing generally induces a more efficient side-trading technology.

${ }^{46}$ Economies of scope in variable costs would imply $\gamma_{\text {dual }}>\psi_{\text {dual }}$, but $-\delta$ is still generally greater under single sourcing, because the added problem of the fixed costs is greater relative to an isolated side trade.

${ }^{47}$ Dual sourcing could reduce specificity of specific investments where specificity is caused by fixed costs. Such an effect would only reinforce the empirical puzzle.
} 
generates a negative correlation between single sourcing and contract length, offering a clear and simple resolution of the empirical puzzle.

Now I analyze the case where variations in sourcing strategies are driven by variations in the importance $(I$ and $E$ ) of adaptation and specific investments. Consider increasing the importance $E$ of specific investments. By proposition 4a, it is optimal to raise contract length $\alpha$, but when the distortion in adaptation incentives gets high enough ( $I$ not too small), it becomes optimal to shift to dual sourcing. Dual sourcing favours adaptation investments, so this shift is accompanied by an upwards jump in $\alpha$. Further increases in $E$ again lead to further increases in $\alpha$. It follows immediately that dual sourcing is associated with longer contracts (greater $\alpha$ ).

Variations in the importance of adaptation investments have a less monotonic effect. When $I$ is very low, it is optimal to focus on protecting specific investments with a long-term contract and dual-sourcing is suboptimal (in the non-trivial case where $F-S>0$ ). As $I$ rises, $\alpha$ should fall, except at the point (for large enough $E$ ) where $I$ is large enough to justify a shift to dual sourcing. At this point, $\alpha$ jumps upwards, before continuing to fall with $I$. The comparison between the average contract lengths associated with dual and single sourcing therefore depends on the exact density distribution of $I$. So the prediction here is ambiguous. My principal contribution is to show that dual sourcing can (and often but not always, will) favour long-term contracting and to identify conditions favouring this outcome.

To extend the relevance of this section to applied work, it is also important to recognize that the side-compatibility advantage of multi-sourcing can sometimes be achieved through "selective outsourcing," whereby a client retains a strong internal IT unit. Indeed, Amex chose this approach. Its internal IT unit credibly competes with IBM to satisfy some of its adaptation needs, so Amex's side-compatibility is not so low. See Lacity et al., (1996) for evidence suggesting that selective outsourcing, like multi-sourcing, increases flexibility.

\subsection{Multiple Clients and Dedication}

Transaction cost theorists have thoroughly analyzed the contracts between coal processors and electric utilities. Expanding on Joskow's (1987) classic approach, Kerkvliet and Shogren (2001) measured the fraction of capacity each coal company dedicates to the contract for supplying coal with its utility partner. They were surprised to find a significant negative correlation between this measure of dedication and contract length. This finding (which is robust to four explanation attempts performed by Kerkvliet and Shogren, 2001) is indeed anomalous given that high dedication plausibly proxies for relationship-specificity which tends to require longer contracts. 
The side-compatibility perspective offers a simple explanation. ${ }^{48}$ High dedication to a specific contract leaves the vendor with less capacity to exploit its adaptations in side-trading, so side-compatibility is low and this induces shorter contracts (proposition 5). To complete this explanation, I consider three ways to endogenize the level of dedication. First, as noted in 6.1 , increasing a coal company's supply commitment eventually induces wasteful investments in capability to satisfy the commitment. An exogenous increase in the distortionary effect of such commitments (e.g., increased difficulty in predicting output) encourage reduced commitment, so the fraction of available capacity dedicated to a contract $(d)$ falls. This increases sidecompatibility as explained in section 2 and therefore facilitates an increase in $\alpha$. Accordingly $\alpha$ and $d$ are negatively correlated, as claimed. Second, if side-trading involves fixed costs and becomes untenable for $d$ above a cut-off level $\hat{d}$, exogenous reductions in $\hat{d}$ lead to reductions in $d$ (assuming adaptations and self-investments are both important). To maintain self-investments, $\alpha$ can and should then be raised to compensate for the fall in $d$. So exogenous shifts in $\hat{d}$ can also explain the negative correlation. A third argument follows from the section 5 observation that when adaptation values increase rapidly over time, it is better to use short, but high intensity (dedicated) contracts. So variation in the rate of technical change or supply uncertainty could similarly generate a negative correlation between length and dedication. ${ }^{49}$

\subsection{Contractual Restrictions}

In my basic model, long-term contracts impose trade obligations without shifting residual control rights, but rights and restrictions are sometimes needed to complement performance contracts. For instance, exclusive territory clauses in a franchise contract (that prevents holdup through increases in the royalty rate) prevent franchisors from holding up franchisees by setting up new units that would compete nearby. As complementary tools for protecting specific investments by franchisees, exclusive territories and contract length should be correlated. Bercovitz (2000) tests for a positive correlation (her fourth hypothesis, H4) in her rich franchising data

\footnotetext{
${ }^{48} \mathrm{An}$ alternative is to argue that contract dedication may proxy for coal vendors that have only one client and therefore (having only paid one set of client-specific fixed costs) have relatively low side-compatibility. By analogy with multi-sourcing, exogenous variation in client-specific fixed costs or the importance of specific investments could explain a positive correlation between contract length and selling to multiple clients. (I focus on the simpler explanation in the text, since Kerkvliet and Shogren (2001) measure dedication relative to available capacity, subtracting prior contractual commitments, so a follow-up study might well find that high dedication is not a good proxy for having only one client in their dataset.)

${ }^{49}$ Also, uncertainty in electricity demand is greater over longer time horizons, so risk averse utilities may prefer to buy coal in shorter term contracts as a way to share demand risk with coal producers. Again, contract dedication would covary negatively to counterbalance length reductions.
} 
set. The puzzle is that she finds no significant correlation. The side-compatibility perspective offers a simple resolution. Exclusivity clauses reduce the side-compatibility of franchisor investments that require local adaptations, and this makes contract length more costly. Franchise contracts do not always need exclusivity to complement them and (by proposition 5) contracts will be longer in these cases. For instance, in low density markets, the franchisor cannot credibly threaten to hold up the franchisee by setting up a new franchise or company unit nearby, so exclusive territories are not needed. Holdup is adequately prevented by the long-term franchise contract fixing royalty rate and fees. However, in denser local markets, exclusivity territories are needed to complement the long-term contract; incentives for franchisor adaptations are then at risk and contracts should be shorter. ${ }^{50}$ This offers a reasonable explanation for the negative correlation.

Interestingly, Bercovitz (2000) also finds an insignificant correlation between exclusivity and her proxy for specificity (franchisor estimates of franchisee set-up costs). Measurement error might explain the insignificant correlation, but the proxy specificity has been successful in other work - see Dnes (1992) and Brickley et al., (2003) (which, as mentioned above, contains strong results supporting proposition 4a). Instead, I offer an explanation based on sidecompatibility and the section 5 idea that adaptation investments become more productive over time. When specificity is low, contracts can be short and exclusivity is a sensible complement to the contract, since each party can earn a reasonable return on its adaptation investments by waiting till the contract expires. Exclusivity is problematic, however, when specificity is important enough to require longer contracts. This countervails against Bercovitz's prediction that exclusivity would be more common where specific investments are more significant. ${ }^{51}$

Contracts regularly seek the very opposite of exclusivity restrictions, by specifying rights to solicit competitive bids on services beyond the baseline contract. ${ }^{52}$ Additionally, IT contracts and industry norms often require standardization and documentation of code, even pressuring providers to cooperate. ${ }^{53}$ Further work could extend my model of contracting and

\footnotetext{
${ }^{50}$ Kaufmann's (1993) Harvard Business case study offers a concrete example of an adaptation problem: Pizza Hut's efforts to develop and implement a Pepsi promotion scheme through home deliveries were frustrated when Pizza Hut had to negotiate with franchisees who preferred to focus on eat-in dining.

${ }^{51}$ Future empirical work that identifies an exogenous source of variation in the use of exclusivity clauses would offer an excellent way to test my theory more directly. Variation in the legality of exclusivity restrictions across U.S. states presents a promising avenue, but restrictive states also tend to restrict contract termination making reported contract length a biased proxy of contract length.

${ }^{52}$ This was common in Goldberg and Erickson's (1987) data on coke supply contracts. It is also very common in IT contracting.

${ }^{53}$ E.g., clause 3.05 in UHS-Unisys obliges Unisys to support third-party software purchased by UHS. Enforcement, however, is difficult - Lacity and Willcocks (1998) report two cases where vendors prevented third-party
} 
side-compatibility to analyze how to assign ownership rights when some investments are partly asset-specific.

\section{Concluding Discussion}

I have analyzed the optimal duration of performance contracting in a bilateral model where both traders make multiple investments. My most important result is that contracts should be shorter when side-compatibility is low and it is important to motivate adaptation investments. By showing that side-compatibility is high in three relevant settings (when a trader has multiple vendors, when long-term contracts do not exhaust the capacity or need for trade, and when there are no exclusivity clauses restricting side-trades), I was able to apply this result to predict a pressure towards longer contracts and resolve the three empirical puzzles from the transaction cost literature.

My market-shielding perspective endogenizes and qualifies the transaction cost idea that long-term contracts have flexibility costs. Formally, I have shown that (unless fully sidecompatible) adaptations can be more cheaply implemented under short-term than long-term contracting. My framework also indicates why renegotiating from a long-term contract is likely to be harder than negotiating from scratch: ${ }^{54}$ competitive bids can reveal information about the cost of adaptations, reducing information asymmetries and with them, the risk of negotiation failure, so long-term contracts that reduce competition (because of limited side-compatibility) increase the risk of failing to negotiate efficient adaptations ex post. ${ }^{55}$

Because of a false presumption that general investments are not at risk of holdup, other formal analyses have neglected how long-term contracts interfere with valuable market forces. Most papers with long-term contracting simply ignored general investments. MacLeod and Malcomson (1993) is an exception, but they only studied one joint trade, thereby precluding the possibility of general investments that require an adapted joint trade. The closest analogy to my market-shielding result is in fact Hart and Moore's (1990) analysis of ownership. In a setting without long-term contracting, they showed how removing ownership rights interferes with access to market forces that could otherwise motivate asset-specific investments. In a setting with long-term contracts, I have shown how a contractual trading obligation shields out market forces that could otherwise motivate adaptation investments.

supply by claiming interference with their maintenance obligations. Standards are perhaps more important for reducing transition costs than side-compatibility - see Beulen and Ribbers (2003).

${ }^{54}$ Many theorists have assumed there is no difference, positing instead an exogenous cost of renegotiation (see e.g., Harris and Holmström, 1987, and Guriev and Kvassov, 2006).

${ }^{55}$ Future work must extend the model to include alternative traders who invest and bid to win new trades. 
My results formally corroborate prior insights from transaction cost theory on the impact of market-thickness, investment specificity, contract effectiveness and uncertainty, and novel results, such as the distinction between the level and substitution effects of changes on contract length and their dependence on the type of investment. Because the model is very tractable (for instance, cross effects and wasteful investments have the exact inverse impact of the corresponding self effects and non-wasteful investments), it is also easy to analyze temporal variation in investment productivity and future work can extend my multi-period setting to allow for richer history-dependence.

In the extensions section, I explained how intermediate breach penalties and menu contracts can raise contractual flexibility. Relational contracting may further enhance the effectiveness of menu contracts, so building on the modeling approach of Baker et al., (2002) presents important work for future analysis. Extending the model to allow for partially measurable costs is also interesting: Bajari and Tadelis (2001) argue that cost-plus contracts are more flexible than fixed-price contracts because renegotiation is then more efficient. Since Bajari and Tadelis (2001) do not consider market forces, combining our models could generate novel predictions. For instance, I conjecture that settings with high side-compatibility will favor fixed-price contracting, since these settings limit the inflexibility concern.

In conclusion, the resolution of the three puzzles and the consistency with the evidence from the transaction cost literature on contract length offers encouraging support for my simple model. Nonetheless, it is vital to now collect empirical data with an eye to creating effective proxies of side-compatibility and the other parameters used to predict contract length. This will permit sharper tests of the model's predictions and improve our ability to explain the design and duration of contracts. 


\section{Appendix}

Proof of Proposition 3. Differentiating the identities in (2) with respect to $\alpha$ and defining $\delta_{e_{j}} \equiv \psi_{e_{j}}-\gamma_{e_{j}}$

$$
\begin{aligned}
\frac{d e_{j}}{d \alpha} & =\left[\frac{-W_{j}^{\prime}\left(e_{j}\right)}{W_{j}^{\prime \prime}\left(e_{j}\right)}\right] \frac{\psi_{e_{j}}-\gamma_{e_{j}}}{1+\alpha \cdot \psi_{e_{j}}+(1-\alpha) \gamma_{e_{j}}}=\frac{-\delta_{e_{j}} W_{j}^{\prime}\left(e_{j}\right)}{H\left(\alpha ; \psi_{e_{j}}, \gamma_{e_{j}}\right) W_{j}^{\prime \prime}\left(e_{j}\right)} \\
\frac{d i_{j}}{d \alpha} & =\left[\frac{-V_{j}^{\prime}\left(i_{j}\right)}{V_{j}^{\prime \prime}\left(i_{j}\right)}\right] \frac{\psi_{i_{j}}-\gamma_{i_{j}}}{1+\alpha \cdot \psi_{i_{j}}+(1-\alpha) \gamma_{i_{j}}}=\frac{-\delta_{e_{j}} V_{j}^{\prime}\left(i_{j}\right)}{H\left(\alpha ; \psi_{i_{j}}, \gamma_{i_{j}}\right) V_{j}^{\prime \prime}\left(i_{j}\right)}
\end{aligned}
$$

The bracketed expressions are positive by Assumption 1. $H$ is always positive by Assumption 2. The sign of $\delta$ is positive for $e_{P}$ and $e_{A}$ and negative for $i_{P}$ and $i_{A}$, by type 1 and 2 definitions. This proves $3(\mathrm{a})$.

Differentiating with respect to $\gamma$ and $\psi$ gives,

$$
\begin{aligned}
\frac{d e_{j}}{d \gamma_{e_{j}}} & =\left[\frac{-W_{j}^{\prime}\left(e_{j}\right)}{W_{j}^{\prime \prime}\left(e_{j}\right)}\right] \frac{1-\alpha}{H\left(\alpha ; \psi_{e_{j}}, \gamma_{e_{j}}\right)} \\
\frac{d e_{j}}{d \psi_{e_{j}}} & =\left[\frac{-W_{j}^{\prime}\left(e_{j}\right)}{W_{j}^{\prime \prime}\left(e_{j}\right)}\right] \frac{\alpha}{H\left(\alpha ; \psi_{e_{j}}, \gamma_{e_{j}}\right)}
\end{aligned}
$$

Both these expressions are positive for $\alpha \in(0,1)$. The first is positive even when $\alpha=0$, the second is positive even when $\alpha=1$. This proves $3(\mathrm{~b})$ since the exact same expressions and observations are valid for $i_{j}$. 3(c) follows from the observations that $e_{j}(1)=e_{j}^{L T C} \leq e_{j}^{*}$ and $i_{j}(0)=i_{j}^{S T C} \leq i_{j}^{*}$ - compare first order conditions (2) at $\alpha=1$ and 0 with first-best conditions (1).

Sufficient conditions for concavity (in $\alpha$ ) of the maximands in (4a) and (4b):

$$
W_{j}^{\prime \prime \prime} W_{j}^{\prime}<4\left(W_{j}^{\prime \prime}\right)^{2} \text { and } V_{j}^{\prime \prime \prime} V_{j}^{\prime}<4\left(V_{j}^{\prime \prime}\right)^{2}
$$

For instance, $W$ and $V$ can take any of the forms, $\sqrt{e},-\frac{1}{e}$ and $\log e$ ).

Proof of sufficiency. The derivative of the maximand in (4a) is,

$$
\begin{aligned}
D & \equiv \sum_{j=P, A}(\underbrace{E_{j}\left(W_{j}^{\prime}\left(e_{j}(\alpha)\right)-1\right) e_{j}^{\prime}(\alpha)}_{D_{e_{j}}}+\underbrace{I_{j}\left(V_{j}^{\prime}\left(i_{j}(\alpha)\right)-1\right) i_{j}^{\prime}(\alpha)}) \\
& =\sum_{j=P, A}\left(\begin{array}{c}
D_{i_{j}}
\end{array}\right)
\end{aligned}
$$

Differentiating the first component with respect to $\alpha$ again gives,

$$
\begin{aligned}
\frac{d D_{e_{j}}}{d \alpha} & =\frac{d}{d \alpha}\left(E_{j}\left(W_{j}^{\prime}\left(e_{j}(\alpha)\right)-1\right) e_{j}^{\prime}(\alpha)\right) \\
& =E_{j}\left(W_{j}^{\prime \prime}\left(e_{j}(\alpha)\right)\left(e_{j}^{\prime}(\alpha)\right)^{2}+\left(W_{j}^{\prime}\left(e_{j}(\alpha)\right)-1\right) e_{j}^{\prime \prime}(\alpha)\right)
\end{aligned}
$$


Now, by $(2), \frac{1}{2} H\left(\alpha ; \psi_{e_{j}}, \gamma_{e_{j}}\right) W_{j}^{\prime}\left(e_{j}\right)=1$ holds for all $\alpha$, and $H^{\prime}(\alpha)=\delta_{e_{j}}$, so $\delta_{e_{j}} W_{j}^{\prime}\left(e_{j}\right)+$ $H W_{j}^{\prime \prime}\left(e_{j}\right) e_{j}^{\prime}(\alpha)=0$ and,

$$
2 \delta_{e_{j}} W_{j}^{\prime \prime}\left(e_{j}\right) e_{j}^{\prime}(\alpha)+H\left(W_{j}^{\prime \prime \prime}\left(e_{j}\right) e_{j}^{\prime}(\alpha)^{2}+W_{j}^{\prime \prime}\left(e_{j}\right) e_{j}^{\prime \prime}(\alpha)\right)=0
$$

So substituting for

$$
\begin{aligned}
e_{j}^{\prime}(\alpha)=\frac{-\delta_{e_{j}} W_{j}^{\prime}\left(e_{j}\right)}{H W_{j}^{\prime \prime}\left(e_{j}\right)}=\frac{-2 \delta_{e_{j}}}{H^{2} W_{j}^{\prime \prime}\left(e_{j}\right)} ; e_{j}^{\prime \prime}(\alpha)=\frac{-e_{j}^{\prime}(\alpha)}{H W_{j}^{\prime \prime}\left(e_{j}\right)}\left(2 \delta_{e_{j}} W_{j}^{\prime \prime}\left(e_{j}\right)-H W_{j}^{\prime \prime \prime}\left(e_{j}\right) e_{j}^{\prime}(\alpha)\right) \\
\frac{d D_{e_{j}}}{d \alpha}=\frac{E_{j} e_{j}^{\prime}}{H W_{j}^{\prime \prime}}\left(H\left(W_{j}^{\prime \prime}\right)^{2} e_{j}^{\prime}+\left(W_{j}^{\prime}-1\right)\left(H W_{j}^{\prime \prime \prime} e_{j}^{\prime}-2 \delta_{e_{j}} W_{j}^{\prime \prime}\right)\right) \\
=\frac{E_{j} e_{j}^{\prime}}{H W_{j}^{\prime \prime}}\left(-\delta_{e_{j}} W_{j}^{\prime \prime} W_{j}^{\prime}+\left(W_{j}^{\prime}-1\right)\left(-\frac{\delta_{e_{j}} W^{\prime} W_{j}^{\prime \prime \prime}}{W_{j}^{\prime \prime}}-2 \delta_{e_{j}} W_{j}^{\prime \prime}\right)\right) \\
=-\frac{\delta_{e_{j}} E_{j} e_{j}^{\prime}}{H}\left(W_{j}^{\prime}+\left(W_{j}^{\prime}-1\right)\left(\frac{W^{\prime} W_{j}^{\prime \prime \prime}}{\left(W_{j}^{\prime \prime}\right)^{2}}+2\right)\right) \\
=-\frac{\delta_{e_{j}} E_{j} e_{j}^{\prime}}{H^{2}}\left((6-2 H)+(2-H) \frac{W^{\prime} W_{j}^{\prime \prime \prime}}{\left(W_{j}^{\prime \prime}\right)^{2}}\right)
\end{aligned}
$$

Since $e_{j}^{\prime}, \delta_{e_{j}}, E_{j}>0$, this expression is negative provided that $\frac{W^{\prime} W_{j}^{\prime \prime \prime}}{\left(W_{j}^{\prime \prime}\right)^{2}}<\frac{6-2 H}{2-H}$ for all $\alpha$. Since $H \in[1,2], \frac{6-2 H}{2-H} \geq 4$, hence $W^{\prime} W_{j}^{\prime \prime \prime}<4\left(W_{j}^{\prime \prime}\right)^{2}$ is clearly sufficient. The term from $\frac{d D_{i_{j}}}{d \alpha}$ is also positive under the parallel condition, because while $\delta_{i_{j}}$ and $i_{j}^{\prime}$ are both negative, their product is still positive. This proves that $\frac{d D}{d \alpha}<0$ for $4 \mathrm{a}$.

Sufficiency for the maximand in $4 \mathrm{~b}$ follows immediately, because setting $E$ and $I$ to unity and rescaling $W$ and $V$ by $\hat{E}$ and $\hat{I}$ does not affect the ratios, $\frac{W^{\prime} W_{j}^{\prime \prime \prime}}{\left(W_{j}^{\prime \prime}\right)^{2}}$ and $\frac{V_{j}^{\prime \prime \prime} V_{j}^{\prime}}{\left(V_{j}^{\prime \prime}\right)^{2}}$.

Proof of Proposition 4a. The first-order condition for the optimization problem (4a) is $D(\mathbf{E}, \mathbf{I} ; \alpha(\mathbf{E}, \mathbf{I}))=0$, for $D$ as defined in (A2). This holds for all $\mathbf{E}$ and $\mathbf{I}$, so applying the Implicit Function Theorem reveals,

$$
\frac{d \alpha}{d E_{j}}=\frac{-\frac{\partial D}{\partial E_{j}}}{\frac{\partial D}{\partial \alpha}}
$$

$\frac{\partial D}{\partial \alpha}<0$ by assumption of concavity (see above for sufficient conditions).

$$
\frac{\partial D}{\partial E_{j}}=\frac{\partial D_{e_{j}}}{\partial E_{j}}=\left(W_{j}^{\prime}\left(e_{j}(\alpha)\right)-1\right) e_{j}^{\prime}\left(\alpha_{j}\right)=\left(\frac{2}{H}-1\right) e_{j}^{\prime}(\alpha)
$$


which is positive since $0<H<2$ and $e_{j}^{\prime}(\alpha)>0$. Hence $\frac{d \alpha}{d E_{j}}>0$. By contrast, $\frac{d \alpha}{d I_{j}}=$ $\frac{-\left(\frac{2}{H}-1\right) i_{j}^{\prime}(\alpha)}{\frac{\partial D}{\partial \alpha}}<0$ since $i_{j}^{\prime}(\alpha)<0$.

Proof of Proposition $4 \mathrm{~b}$. This is slightly more complex, since $e$ and $i$ now depend on $E$ and $I: e_{j}\left(\alpha, \hat{E}_{j}\right)$ and $i_{j}\left(\alpha, \hat{I}_{j}\right)$ are such that $H \hat{E}_{j} W_{j}^{\prime}\left(e_{j}\left(\alpha, \hat{E}_{j}\right)\right)=2, H \hat{I}_{j} V_{j}^{\prime}\left(i_{j}\left(\alpha, \hat{I}_{j}\right)\right)=2$. So

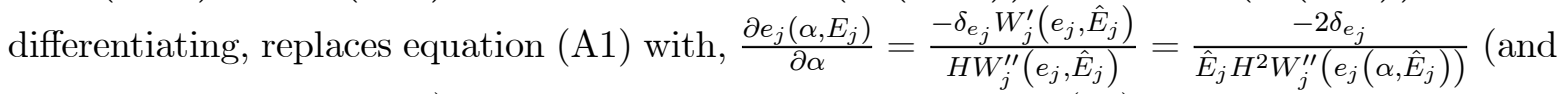
a similar expression for $i_{j}$ ). The derivative of the maximand in (4b) is,

$$
\begin{aligned}
\hat{D} & \equiv \sum_{j=P, A}(\underbrace{\left(\hat{E}_{j} W_{j}^{\prime}\left(e_{j}\left(\alpha, \hat{E}_{j}\right)\right)-1\right) e_{j}^{\prime}\left(\alpha, \hat{E}_{j}\right)}_{\hat{D}_{e_{j}}}+\underbrace{\left(\hat{I}_{j} V_{j}^{\prime}\left(i_{j}\left(\alpha, \hat{I}_{j}\right)\right)-1\right) i_{j}^{\prime}\left(\alpha, \hat{I}_{j}\right)}_{\hat{D}_{i_{j}}})(\mathrm{A} 4) \\
& =\sum_{j=P, A}(\underbrace{})
\end{aligned}
$$

So,

$$
\begin{aligned}
\frac{\partial \hat{D}}{\partial \hat{E}_{j}} & =\frac{\partial \hat{D}_{e_{j}}}{\partial \hat{E}_{j}}=\frac{\partial}{\partial \hat{E}_{j}}\left(\left(\frac{2}{H}-1\right) \frac{-2 \delta_{e_{j}}}{\hat{E}_{j} H^{2} W_{j}^{\prime \prime}\left(e_{j}\left(\alpha, \hat{E}_{j}\right)\right)}\right) \\
& =\frac{2}{H^{2}}\left(\frac{2}{H}-1\right) \delta_{e_{j}} \frac{\partial}{\partial \hat{E}_{j}}\left(\frac{-1}{\hat{E}_{j} W_{j}^{\prime \prime}\left(e_{j}\left(\alpha, \hat{E}_{j}\right)\right)}\right)
\end{aligned}
$$

As $H<2$ by assumption 1 and $\delta_{e_{j}}>0$ by definition of type 1 , this has the same sign as $\frac{\partial}{\partial \hat{E}_{j}}\left(\hat{E}_{j} W_{j}^{\prime \prime}\left(e_{j}\left(\alpha, \hat{E}_{j}\right)\right)\right)$. Differentiating (5) $\left(\frac{1}{2} H\left(\alpha ; \psi_{e_{j}}, \gamma_{e_{j}}\right) \hat{E}_{j} \cdot W_{j}^{\prime}\left(e_{j}\left(\alpha, \hat{E}_{j}\right)\right) \equiv 1\right)$ with respect to $\hat{E}_{j}$ and substituting shows that,

$$
\frac{\partial}{\partial \hat{E}_{j}}\left(\hat{E}_{j} W_{j}^{\prime \prime}\left(e_{j}\left(\alpha, \hat{E}_{j}\right)\right)\right)=W_{j}^{\prime \prime}+\hat{E}_{j} W_{j}^{\prime \prime \prime} \frac{\partial e_{j}}{\partial \hat{E}_{j}}=W_{j}^{\prime \prime}+\hat{E}_{j} W_{j}^{\prime \prime \prime} \frac{-W_{j}^{\prime}}{\hat{E}_{j} W_{j}^{\prime \prime}}
$$

As $W_{j}^{\prime \prime}<0$ by assumption 1 , this has the same sign as $W_{j}^{\prime} W_{j}^{\prime \prime \prime}-\left(W_{j}^{\prime \prime}\right)^{2}$ which is positive by assumption 3. Hence, $\frac{\partial D}{\partial \hat{E}_{j}}>0$ so (A2) reveals that $\frac{d \alpha}{d \hat{E}_{j}}>0$ as claimed. Again $\frac{d \alpha}{d I_{j}}$ takes the opposite sign since $\delta_{i_{j}}<0$.

Proof of Proposition 5. I prove for the case of $e_{j}$ (same arguments hold for $i_{j}$ ). To study changes in $\delta$ with $H$ fixed at $H=\hat{H}$ for $\alpha=\hat{\alpha}$, differentiating $D$ at $\alpha=\hat{\alpha}$ simply gives: $\left.\frac{\partial D}{\partial \delta_{e_{j}}}\right|_{H_{e_{j}}(\hat{\alpha})=\hat{H}_{e_{j}}}=\left(\left(\frac{2}{\hat{H}_{e_{j}}}-1\right) \frac{2}{\hat{H}_{e_{j}}{ }^{2}}\left(\frac{1}{-W^{\prime \prime}}\right)\right)>0\left(\right.$ as $\hat{H}_{e_{j}}<2$ and $\left.W^{\prime \prime}<0\right)$. Applying the Implicit Function Theorem to the first-order condition $(D(\boldsymbol{\psi}, \boldsymbol{\gamma} ; \alpha(\boldsymbol{\psi}, \boldsymbol{\gamma})) \equiv 0)$ gives,

$$
\left.\frac{\partial \alpha}{\partial \delta_{e_{j}}}\right|_{H_{e_{j}}(\hat{\alpha})=\hat{H}_{e_{j}}}=-\frac{\left.\frac{\partial D}{\partial \delta_{e_{j}}}\right|_{H_{e_{j}}(\hat{\alpha})=\hat{H}_{e_{j}}}}{\frac{\partial D}{\partial \alpha}}
$$

Since $\frac{\partial D}{\partial \alpha}<0$, this substitution effect is positive at $\alpha=\hat{\alpha}$, so $\alpha$ increases as claimed. 
Similarly, the Implicit Function Theorem gives the level effect of changing $H_{e_{j}}$ with $\delta_{e_{j}}$ fixed at $\hat{\delta}:\left.\left.\frac{\partial \alpha}{\partial H_{e_{j}}}\right|_{\psi_{e_{j}}-\gamma_{e_{j}}=\hat{\delta}} \stackrel{\text { sign }}{=} \frac{\partial D}{\partial H_{e_{j}}}\right|_{\psi_{e_{j}}-\gamma_{e_{j}}=\hat{\delta}}$ and $\left.\frac{\partial D}{\partial H_{e_{j}}}\right|_{\delta_{e_{j}}=\hat{\delta}_{e_{j}}}=\left.\frac{1}{\hat{\delta}_{e_{j}}} \frac{\partial D_{e_{j}}}{\partial \alpha}\right|_{\hat{\delta}_{e_{j}}}$, since $H_{e_{j}} \equiv$ $\left(1+\gamma_{e_{j}}+\alpha \delta_{e_{j}}\right)$ and $D_{e_{j}}$ depends on $\alpha$ through $H_{e_{j}}$. Now $\frac{\partial D_{e_{j}}}{\partial \alpha}<0$, so this level effect has the same sign as $-\hat{\delta}_{e_{j}}$. The same argument applies for $i_{j}$.

Proof of Propositions $\mathbf{6 a}$ and $\mathbf{6 b}$. The maximand (4) is now extended by the additive term, $\sum_{j=P, A}\left(-K_{j} k_{j}\left(\alpha, \hat{K}_{j}\right)\right)$, where $H(\alpha) \hat{K}_{j} \cdot B_{j}^{\prime}\left(k_{j}\left(\alpha, \hat{K}_{j}\right)\right) \equiv 2$. So differentiating with respect to $\alpha, D$ is extended by addition of $\sum_{j=P, A}\left(-K_{j} \frac{\partial k_{j}\left(\alpha, \hat{K}_{j}\right)}{\partial \alpha}\right)$. Now $\frac{\partial k_{j}\left(\alpha, \hat{K}_{j}\right)}{\partial \alpha}=\frac{-\delta_{k_{j}} B_{j}^{\prime}}{H B_{j}^{\prime \prime}}=$ $\frac{-2 \delta_{k_{j}}}{H^{2} \hat{K}_{j} B_{j}^{\prime \prime}}$, so I can guarantee that the optimand's concavity increases (i.e., $\frac{\partial D}{\partial \alpha}<0$ ) by showing that $\frac{d}{d \alpha}\left(\frac{\delta_{k_{j}}}{H^{2} \hat{K}_{j} B_{j}^{\prime \prime}\left(k_{j}\left(\alpha, \hat{K}_{j}\right)\right)}\right)<0$ which is equivalent to,

$$
\begin{aligned}
\frac{d}{d \alpha}\left(\delta_{k_{j}} H(\alpha)^{2} B_{j}^{\prime \prime}\left(k_{j}\left(\alpha, \hat{K}_{j}\right)\right)\right) & >0 \\
\delta_{k_{j}}\left(2 H \delta_{k_{j}} B_{j}^{\prime \prime}+H^{2} B_{j}^{\prime \prime \prime}\left(\frac{-2 \delta_{k_{j}}}{H^{2} \hat{K}_{j} B_{j}^{\prime \prime}}\right)\right) & >0 \\
\delta_{k_{j}}^{2}\left(\left(B_{j}^{\prime \prime}\right)^{2}-B_{j}^{\prime} B_{j}^{\prime \prime \prime}\right) & <0 \\
B_{j}^{\prime} B_{j}^{\prime \prime \prime} & >\left(B_{j}^{\prime \prime}\right)^{2}
\end{aligned}
$$

So, a sufficient (often far from necessary condition) for regularity of the optimization problem is that $B_{j}(\cdot)$ satisfies assumption 3. By the Implicit Function Theorem, $\frac{d \alpha}{d K_{j}}=\frac{-\frac{\partial D}{\partial K_{j}}}{\frac{\partial D}{\partial \alpha}}$ and this takes the same sign as $\frac{\partial D}{\partial K_{j}}=-\frac{\partial k_{j}\left(\alpha, \hat{K}_{j}\right)}{\partial \alpha}=\frac{\delta_{k_{j}} B_{j}^{\prime}}{H B_{j}^{\prime \prime}}$ which has the same sign as $-\delta_{k_{j}}$.

Similarly, $\frac{d \alpha}{d \hat{K}_{j}}$ takes the same sign as,

$$
\begin{aligned}
\frac{\partial D}{\partial \hat{K}_{j}} & =-K_{j} \frac{\partial^{2} k_{j}\left(\alpha, \hat{K}_{j}\right)}{\partial \hat{K}_{j} \partial \alpha}=-K_{j} \frac{\partial}{\partial \hat{K}_{j}}\left(\frac{-2 \delta_{k_{j}}}{H^{2} \hat{K}_{j} B_{j}^{\prime \prime}\left(k_{j}\left(\alpha, \hat{K}_{j}\right)\right)}\right) \\
& =\frac{2 \delta_{k_{j}} K_{j}}{H^{2}} \frac{\partial}{\partial \hat{K}_{j}}\left(\frac{1}{\hat{K}_{j} B_{j}^{\prime \prime}\left(k_{j}\left(\alpha, \hat{K}_{j}\right)\right)}\right) \\
& =-\frac{2 \delta_{k_{j}} K_{j}}{\left(H \hat{K}_{j} B_{j}^{\prime \prime}\left(k_{j}\left(\alpha, \hat{K}_{j}\right)\right)\right)^{2}}\left(B_{j}^{\prime \prime}\left(k_{j}\left(\alpha, \hat{K}_{j}\right)\right)+\hat{K}_{j} B_{j}^{\prime \prime \prime}\left(k_{j}\left(\alpha, \hat{K}_{j}\right)\right)\left(-\frac{B_{j}^{\prime}}{\hat{K}_{j} B_{j}^{\prime \prime}}\right)\right) \\
& =-\delta_{k_{j}} \frac{2 K_{j}}{\left(-B_{j}^{\prime \prime}\right)\left(H \hat{K}_{j} B_{j}^{\prime \prime}\right)^{2}}\left(B_{j}^{\prime} B_{j}^{\prime \prime \prime}-\left(B_{j}^{\prime \prime}\right)^{2}\right)
\end{aligned}
$$

(I used $\frac{\partial k\left(\alpha, \hat{K}_{j}\right)}{\partial \hat{K}}=-\frac{B_{j}^{\prime}}{\hat{K}_{j} B_{j}^{\prime \prime}}$ in the second simplification here.) Assumption 3 on $B_{j}$ implies that 
this takes the same sign as $-\delta_{k_{j}}$. So $\alpha$ increases with $\hat{K}_{j}$ for type 2 investments and decreases with $\hat{K}_{j}$ for type 1 investments.

Proof of Proposition 7. Given the optimality of joint trade (under $Z$ ) in each subperiod, $\mathrm{P}$ and A's problem is,

$$
\max _{\alpha} \sum_{j=P, A} \sum_{n=1}^{N}\left(\hat{E}_{j, n} \cdot W_{j}\left(e_{j}\left(\alpha, \hat{E}_{j}\right)\right)+\hat{I}_{j, n} \cdot V_{j}\left(i_{j}\left(\alpha, \hat{I}_{j}\right)\right)-\left(e_{j}\left(\alpha, \hat{E}_{j}\right)+i_{j}\left(\alpha, \hat{I}_{j}\right)\right)\right)
$$

which is equivalent to (4b) given that $\hat{E}_{j}=\sum_{n=1}^{N} \hat{E}_{j, n}$ and $\hat{I}_{j}=\sum_{n=1}^{N} \hat{I}_{j, n}$. The first-order conditions defining $e_{j}\left(\alpha, \hat{E}_{j}\right)$ and $i_{j}\left(\alpha, \hat{I}_{j}\right)$ (derived in the text) are identical to those (equation 5) applying to proposition $4 \mathrm{~b}$. So $\mathrm{P}$ and A's problem is equivalent to that in proposition 4b. Setting $\hat{E}_{j}=\hat{I}_{j}=1$ replicates the basic optimization problem from which propositions 1-6 were derived. Furthermore, those results hold for the tradeoff in $L$ since variation in $L$ is equivalent to variation in $\alpha$.

\section{References}

[1] Aghion, Philippe, and Patrick Bolton, 1987, "Contracts as a Barrier to Entry," American Economic Review, 77, pp. 388-401.

[2] Allen, Douglas and Dean Lueck, 1995, "Risk Preferences and the Economics of Contracts," American Economic Review, 85(2), pp. 447-51.

[3] Allen, Douglas and Dean Lueck, 1999, "The Role of Risk in Contract Choice," Journal of Law, Economics, and Organization, 15(3), pp. 704-36.

[4] Arruñada, Benito and Xosé Vázquez, 2004, "Contract Manufacturing: Does the Manufacturing Corporation Have a Future?" Universia Business Review.

[5] Bajari, Patrick and Steven Tadelis, 2001, "Incentives versus Transaction Costs: A Theory of Procurement Contracts", Rand Journal of Economics, 32:3, pp. 387-407.

[6] Baker, George, Robert Gibbons and Kevin J. Murphy, 2002, "Relational Contracts and the Theory Of The Firm," The Quarterly Journal of Economics, 117(1), pp. 39-84.

[7] Bandiera, Oriana, 2002, "Contract Duration and Investment Incentives: Evidence from Land Tenancy Agreements", Centre for Economic Policy Research, No.3032.

[8] Bercovitz, Janet, 2000, "An Analysis of Contract Provisions in Business Format Franchise Agreements," Duke mimeo.

[9] Beulen, Erik, and Pieter Ribbers, 2003, "IT Outsourcing Contracts: Practical Implications of the Incomplete Contract Theory," Institute of Electrical and Electronics Engineers. 
[10] Brickley, James, Sanjog Misra, and Lawrence Van Horn, 2003, "Contract Duration: Evidence from Franchise Contracts," mimeo.

[11] Che, Yeon-Koo and Donald Hausch, 1999, "Cooperative Investments and the Value of Contracting," American Economic Review, 89(1), pp. 125-147.

[12] Che, Yeon-Koo and József Sákovics, 2004, "Contractual Remedies to the Holdup Problem: A Dynamic Perspective," Wisconsin mimeo.

[13] Computer Weekly, 2002, “£25M Deal sets HBOS on path to a single platform for insurance," ComputerWeekly.com.

[14] CORI, Contracting and Organizations Research Institute, University of MissouriColumbia (http://cori.missouri.edu).

[15] Crocker, Keith and Scott Masten, 1988, "Mitigating Contractual Hazards: Unilateral Options and Contract Length," Rand Journal of Economics, 19(3) pp. 327-43.

[16] Currie, Wendy "Using multiple suppliers to mitigate the risk of IT outsourcing at ICI and Wessex Water," 1998, Journal of Information Technology, 13, pp. 169-80.

[17] DiSabatino, Jennifer, 2001, "Xerox, EDS Sign Outsourcing, Joint Marketing Agreements," ComputerWorld.com.

[18] Dnes, Anthony, 1992, "Unfair Contractual Practices and Hostages in Franchise Contracts," Journal of Institutional and Theoretical Economics, 148, pp. 484-504.

[19] Economist, 2001, "Old Tricks For New Chips," April 19.

[20] Edlin, Aaron and Stefan Reichelstein (1996), "Hold-ups, Standard Breach Remedies and Optimal Investment," American Economic Review, 86, pp. 478-501.

[21] Ellman, Matthew, 1999, "Essays on the Economics of Organization," doctoral dissertation, Harvard.

[22] Ellman, Matthew, 2006, "Specificity Revisited: The Role of Cross-Investments," forthcoming Journal of Law, Economics and Organization.

[23] Farrell, Joseph, and Carl Shapiro, 1989, "Optimal Contracts with Lock-in," American Economic Review, 79(1)5, pp. 51-68.

[24] Goldberg, Victor, and John Erickson, 1987, "Quantity and Price Adjustment in LongTerm Contracts: A Case Study of Petroleum Coke," Journal of Law and Economics, 30, pp. 369-98.

[25] González-Díaz, Manuel and López-Bayón, Susana, 2002, "Long-Term Versus Short-Term Subcontracting: A Transaction Cost Analysis," Oviedo mimeo.

[26] Grout, Paul, 1984, "Investment and Wages in the Absence of Binding Contracts: A Nash Bargaining Approach," Econometrica, 52, pp. 449-60. 
[27] Grossman, Sanford and Oliver Hart, 1986, "The Costs and Benefits of Ownership: A Theory of Vertical and Lateral Integration," Journal of Political Economy, 94, pp. 691719 .

[28] Guriev, Sergei and Dmitri Kvassov, 2006, "Contracting on Time," forthcoming, American Economic Review.

[29] Harris, Milton and Bengt Holmström, 1987, "On the Duration of Agreements," International Economic Review, 28, pp. 389-406.

[30] Hart, Oliver, 1995, "Firms, Contracts and Financial Structure," Oxford: Oxford University Press.

[31] Hart, Oliver and John Moore, 1990, "Property Rights and the Nature of the Firm," Journal of Political Economy, 98, pp. 1119-58.

[32] Hart, Oliver, Andrei Shleifer and Robert Vishny, 1997, "The Proper Scope of Government: Theory and an Application to Prisons," Quarterly Journal of Economics, 112(4), pp.112661 .

[33] Hoffman, Thomas, 2002, "Utility-Based Computing: More Than Meets the Eye," ComputerWorld.com.

[34] Holmström, Bengt, and Paul Milgrom, 1991, "Multi-Task Principal-Agent Analyses: Incentive Contract, Asset Ownership and Job Design," Journal of Law, Economics and Organization, 7, pp. 24-52.

[35] Input Market Development Services, 2004, "Federal IT Outsourcing Spending To Reach $\$ 15$ Billion," US Government IT 2004 - An Input Guide.

[36] Joskow, Paul, 1987, "Contract Duration and Relationship-Specific Investments: Empirical Evidence from Coal Markets," American Economic Review, 77(1), pp. 168-85.

[37] Kaufmann, Patrick, 1993, "Pizza Hut," Harvard Business Case Study 9-588-011.

[38] Kerkvliet, Joe and Jason Shogren, 2001, "The Determinants of Coal Contract Duration for the Powder River Basin," Journal of Institutional and Theoretical Economics, 4, pp. 604-22.

[39] Klein, Benjamin, Robert Crawford, and Armen Alchian, 1978, "Vertical Integration, Appropriable rents, and the Competitive Contracting Process," Journal of Law and Economics, 21(2), pp. 297-326.

[40] Klein, Benjamin and Kevin Murphy, 1997, "Vertical Integration as a Self-Enforcing Contractual Arrangement," American Economic Review, 87(2), pp. 415-20.

[41] Koch, Christopher, 2003, "If It Looks Like an Outsourcing Deal and Walks Like an Outsourcing Deal," CIO Magazine, July 1.

[42] Lacity, Mary and Leslie Willcocks, 1998, "An Empirical Investigation of Information Technology Sourcing Practices: Lessons from Experience," Management Information Systems Quarterly 22(3), pp. 363-408. 
[43] Lacity, Mary, Leslie Willcocks and David Feeny, 1996, "The Value Of Selective IT Sourcing," Sloan Management Review, 37(3), pp. 13-25.

[44] Lee, Hau and David Hoyt, 2001, "Solectron: From Contract Manufacturer to Global Supply Chain Integrator", Harvard Business School Case, GS24.

[45] López-Bayón, Susana and Juan Ventura, 2001, "Outsourcing in the Electronics Industry. Determinants of Contract Duration," Economía Industrial, 341, pp. 113-22.

[46] MacLeod, Bentley and James Malcomson, 1993, "Investments, Hold-up, and the Form of Market Contracts," American Economic Review, 83(4), pp. 811-37.

[47] Masten, Scott and Stéphane Saussier, 2002, "Econometrics Of Contracts: An Assessment Of Developments In The Empirical Literature On Contracting," in Economics of Contracts: Theories and Applications, Brousseau E. \& Glachant J-M Eds, Cambridge University Press.

[48] National Audit Office (NAO), 2001, "NIRS 2: Contract Extension; Report by Sir John Bourn, Comptroller and Auditor General," NAO Report.

[49] Osborne, Martin and Ariel Rubinstein, 1990, "Bargaining and Markets," San Diego, CA: Academic Press.

[50] Pruitt, Scarlet, 2004, "Offshoring Helps IT Services Grow 6\% in 2003," ComputerWeekly.com

[51] Rogerson, William, 1984, "Efficient Reliance and Damage Measures for Breach of Contract", Rand Journal of Economics, 15, pp. 39-53.

[52] Salanié, Bernard, 1997, "The Economics of Contracts: A Primer," MIT press.

[53] Segal, Ilya and Michael Whinston, 2000, "Exclusive Contracts and Protection of Investments," Rand Journal of Economics, 31, pp. 603-633.

[54] Shavell, Steven, 1984, "The Design of Contracts and Remedies for Breach," Quarterly Journal of Economics, 99(1), pp. 121-48.

[55] Singer, Michael, 2004, "Nokia, HP 'Visualize' Mobile Radio," InternetNews.com April 14.

[56] Tirole, Jean, 1990, "The Theory of Industrial Organization," Cambridge Mass. MIT Press.

[57] Watson, Joel, 2005, "Contract, Mechanism Design, and Technological Detail," San Diego mimeo.

[58] Weiss, Todd, 2002, "American Express Signs \$4B IT Services Deal With IBM," ComputerWorld.com

[59] Weiss, Todd and Juan-Carlos Perez, 2003, "P\&G Awards \$3B Outsourcing Contract to HP," ComputerWorld.com.

[60] Williamson, Oliver, 1985, "The Economic Institutions of Capitalism," Free Press, New York. 